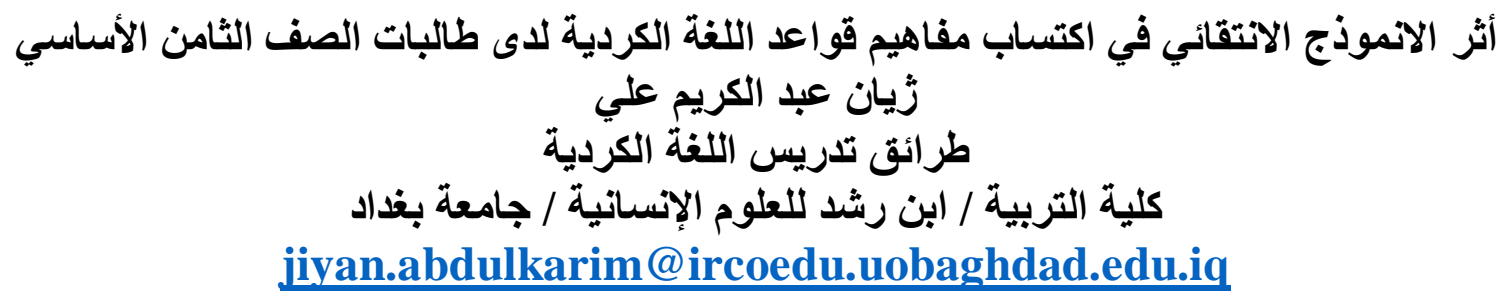

DOI: https://doi.org/10.36231/coedw/vol30no4.8

Received 1/6/2019
Accepted 1/12/2019

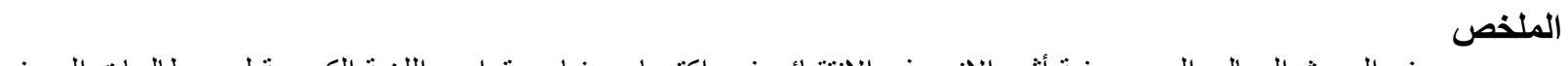

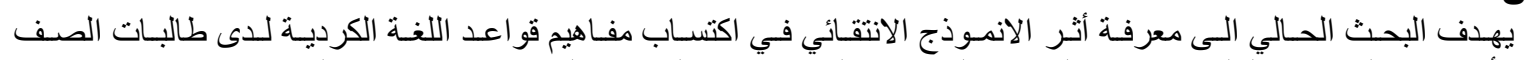

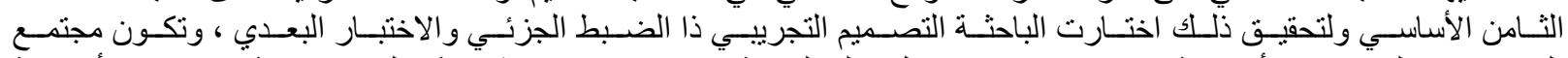

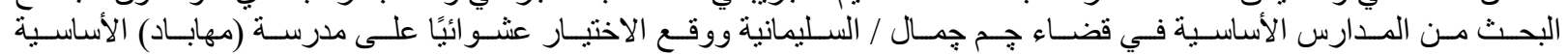

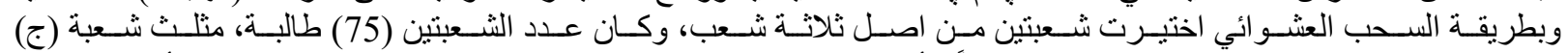

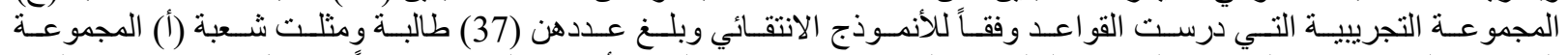

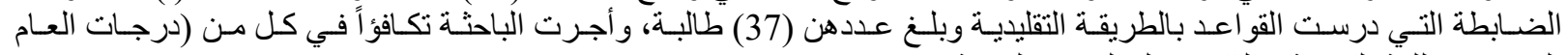

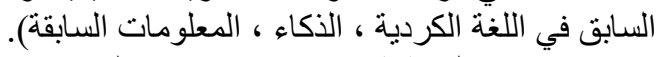

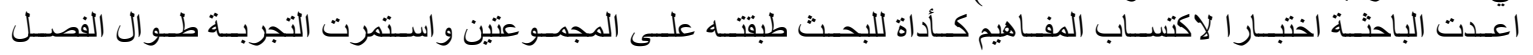

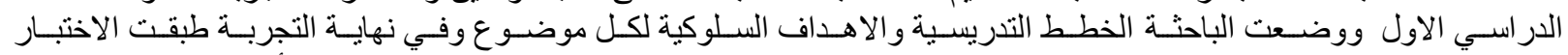

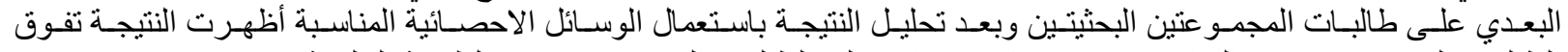

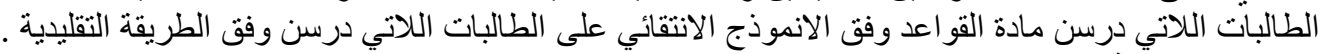

$$
\begin{aligned}
& \text { الكلمات المفتاحية : الانموذج الانتقائي , المفاهيم , القو اعد الكردئ الانقية الكردية }
\end{aligned}
$$

\title{
The Impact of the Selective Model on the Acquisition of Kurdish Grammar Concepts among Female Students in the Eighth Grade Jiyan Abdulkarim Ali
}

Methods of teaching the Kurdish language

University of Baghdad-Faculty of Education Ibn Rushd for Human Sciences Jiyan.abdulkarim@gmail.com

\begin{abstract}
This research aims to identify the impact of the selective model in acquiring the concepts of Kurdish grammar among female students in the eighth grade, and to achieve the goal of research, the researcher selected the experimental design with partial control and dimensional testing; the sample includes basic schools in the Chim district of Chamal/ Sulaymaniyah and randomly selected the basic school (Maha $\mathrm{Bad})$ to be the field of application of the experiment and the random drawing method was chosen: two out of three sections and the number of students of the two sections is (75) students; section (C) represents the experimental group that studied the rules according to the selective model and its number is (37) students, while section (A) represents the controlling group that studied the rules using the traditional way and its number is (37) students, and the researcher conducted a parity in the variables (degrees of the previous year in the Kurdish language, intelligence, previous information.

The researcher prepared a test concerning the acquisition of concepts as a tool for research applied to the research groups and the experiment continued a full semester (first semester) during which the teacher of grammar taught the two groups of research according to the teaching plans and behavioral goals developed by the researcher for each topic. At the end of the experiment, the research tool has been applied for the research groups and after analyzing the results statistically using T-Test for two independent samples. The result showed the superiority of the students of the experimental group who studied the material of the rules according to the selective model of the students of the controlling group.
\end{abstract}

Keywords: Eclectic Model, Concepts, Kurdish Grammar 


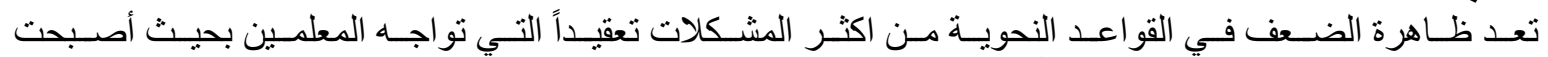

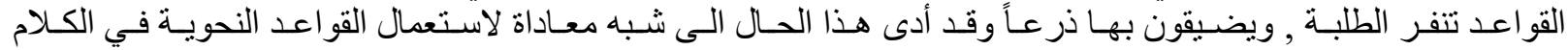

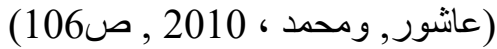

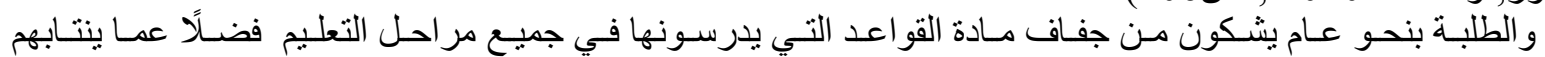

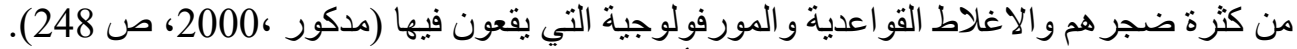

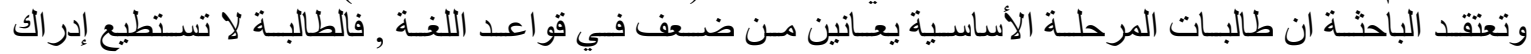

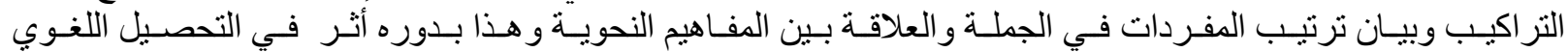

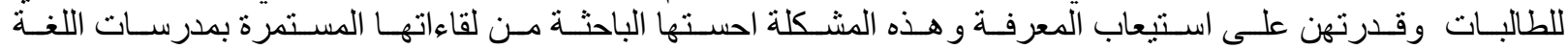

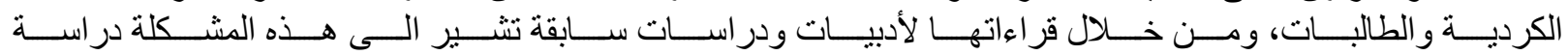

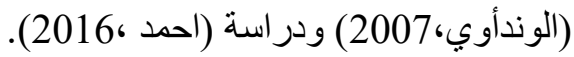

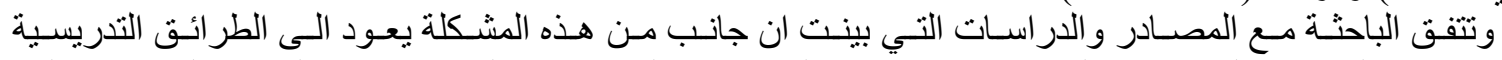

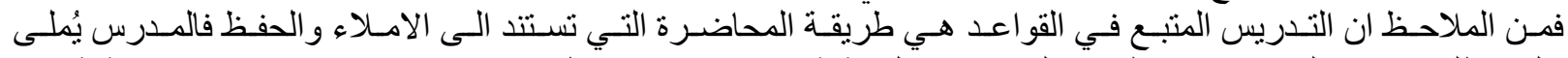

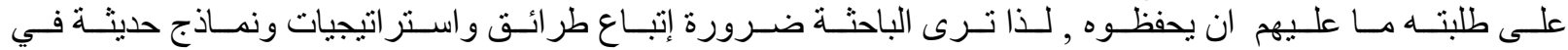
تدريس القو اعد.

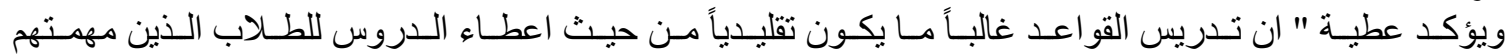

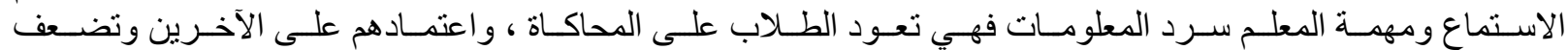

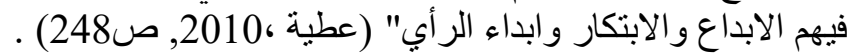

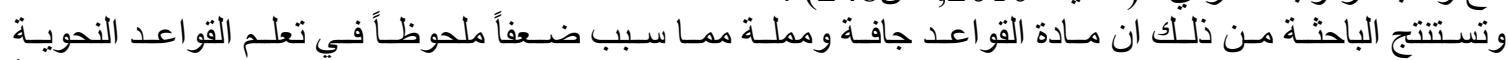

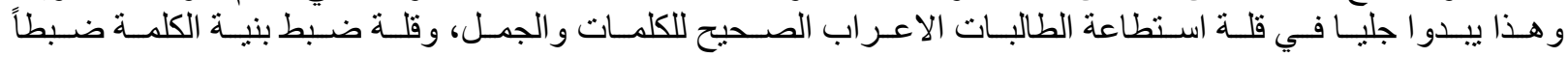

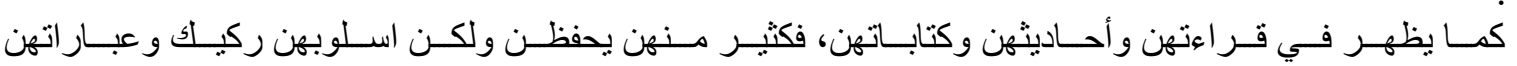

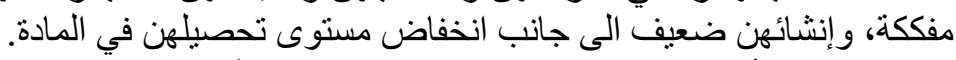

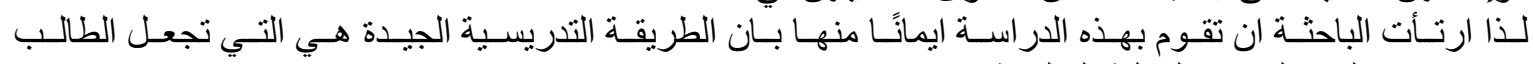
مشاركا إيجابيا لا متلقيا سلبيا في العطلية التعليمية.

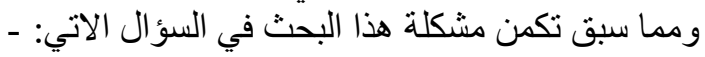
هل للأنموذج الانتقائي أثر في اكتساب مفاهيم قو اعد اللغة الكردية لائ طالبات الصف الثنامن الأساسي.

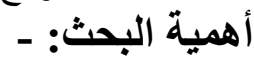

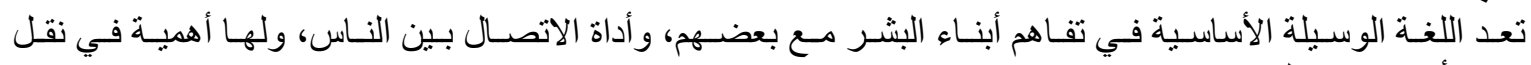

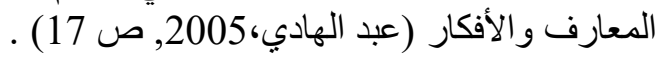

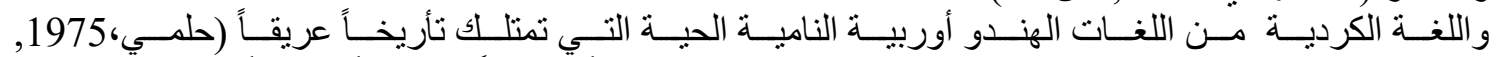

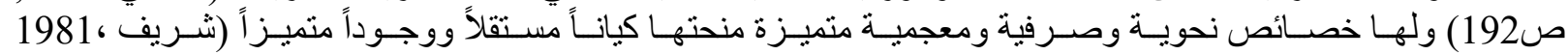

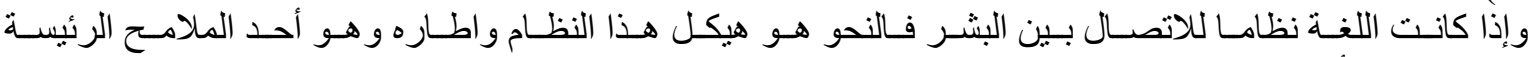

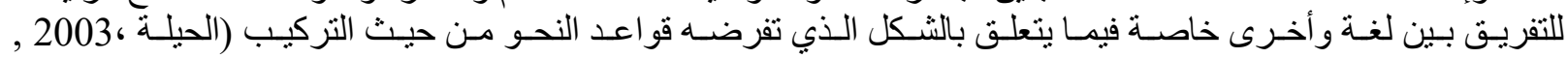

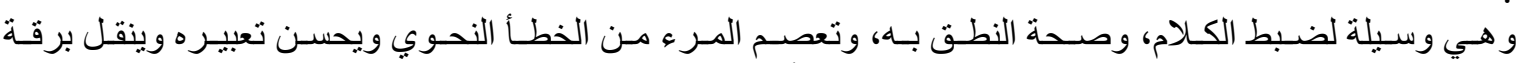
ص1) (1)

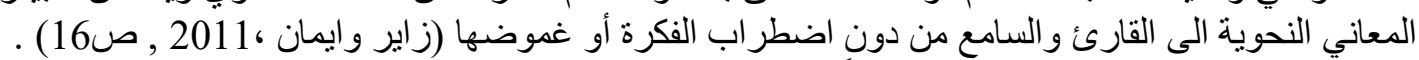

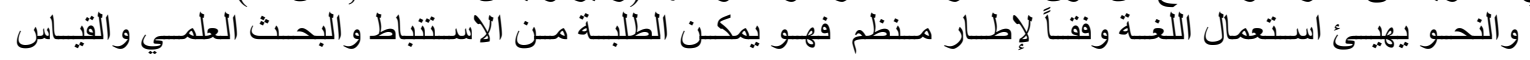

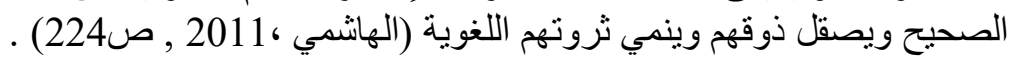

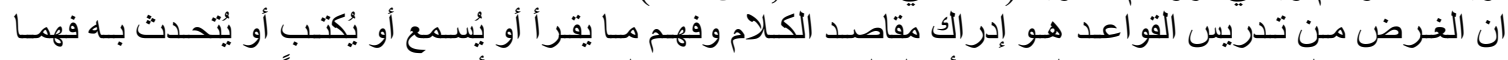

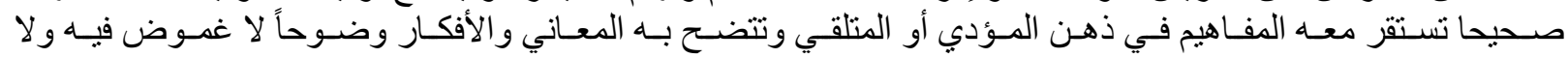

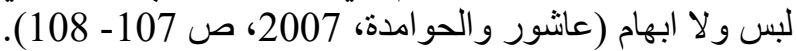

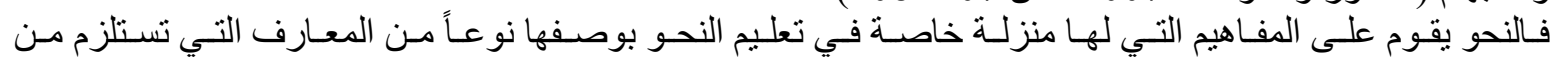

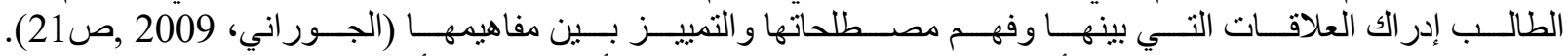

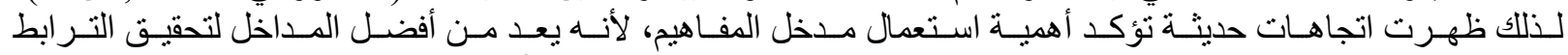

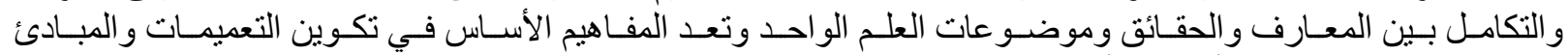

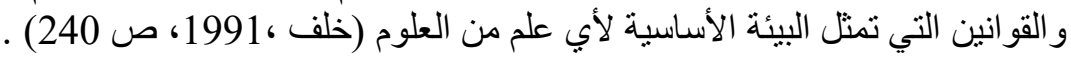




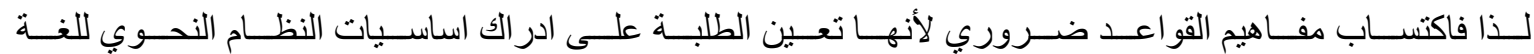

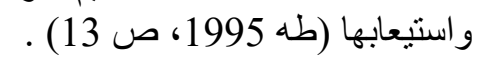

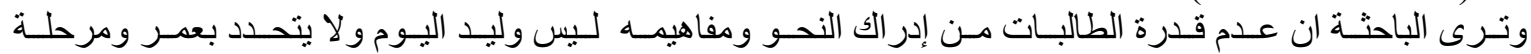

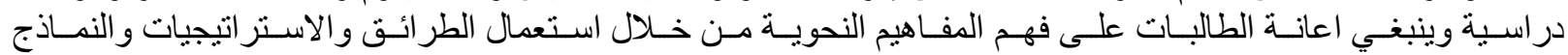
التدريسية المناسبة.

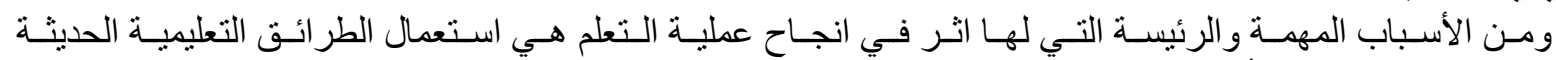

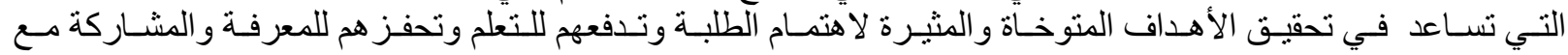

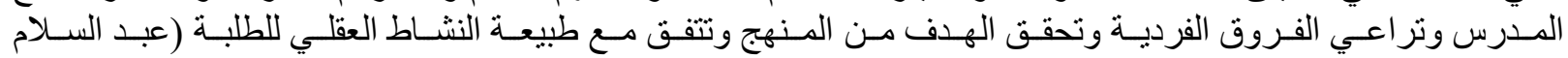
.

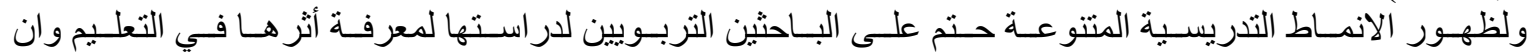

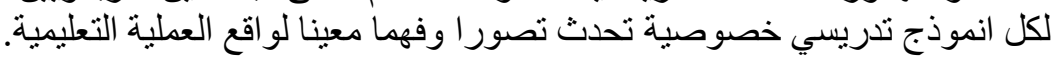

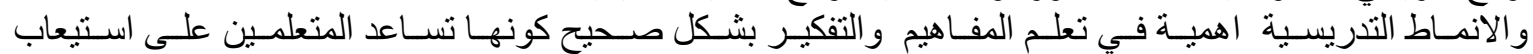

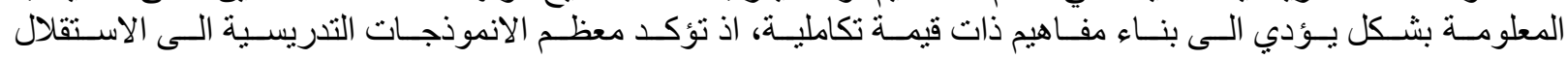

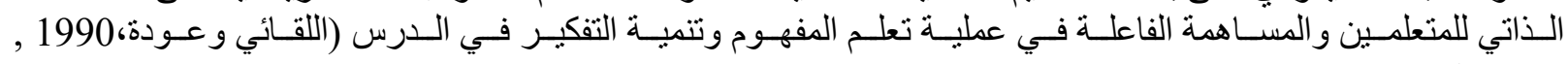
ص141) منان

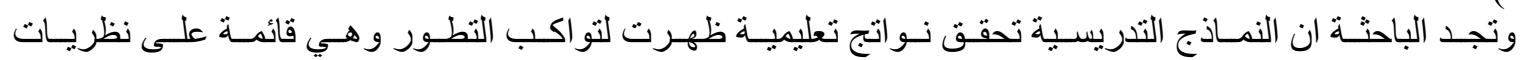

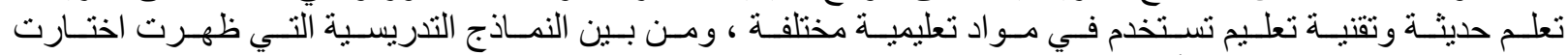

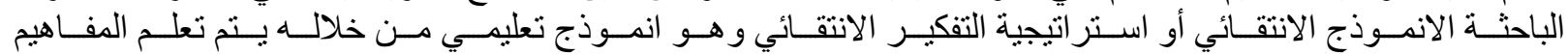

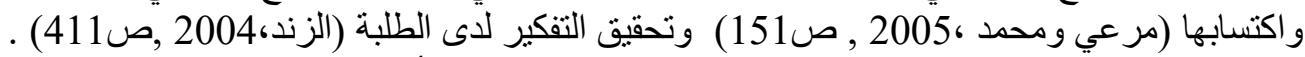

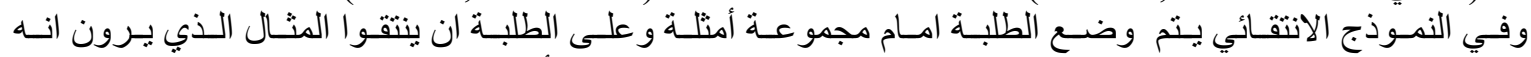

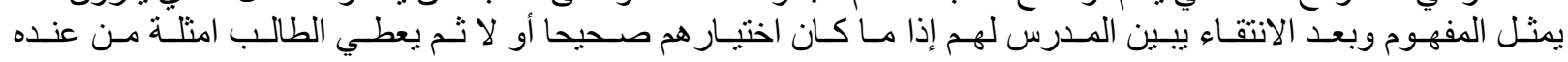

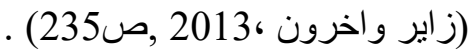

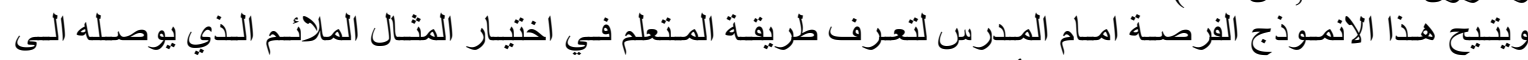

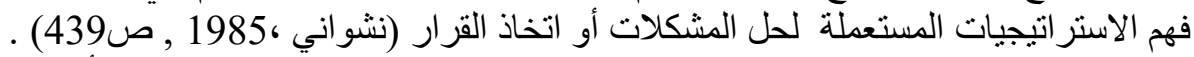

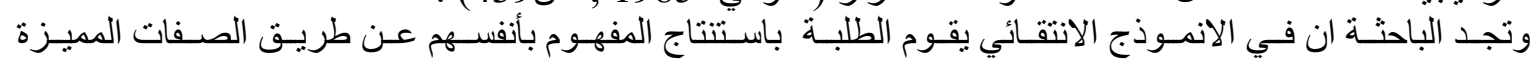

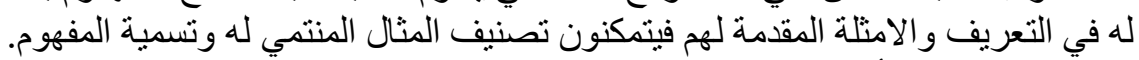

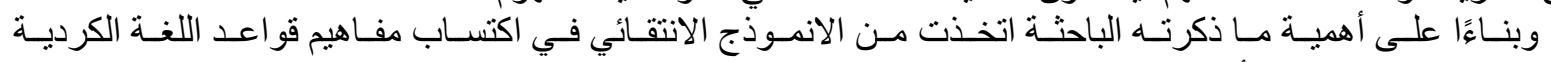

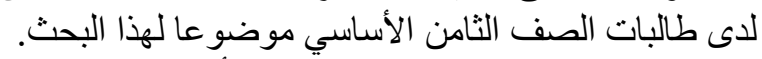

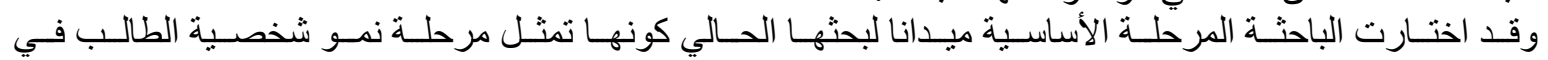

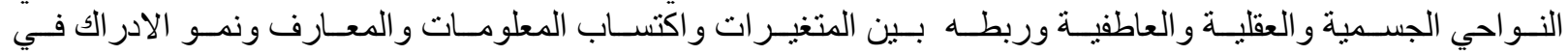

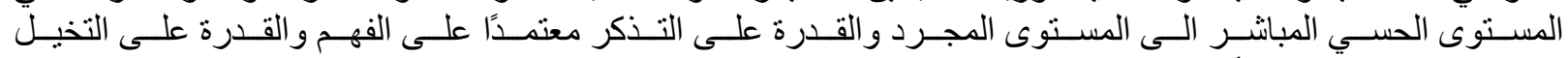

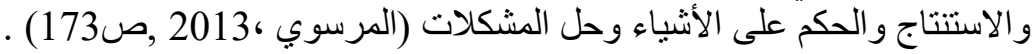

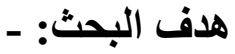

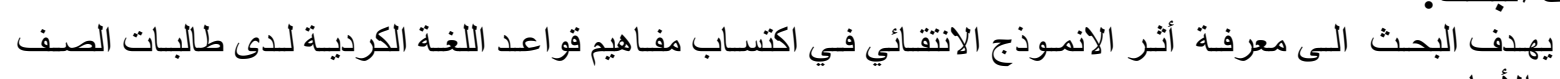
الثامن الأساسي.

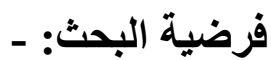

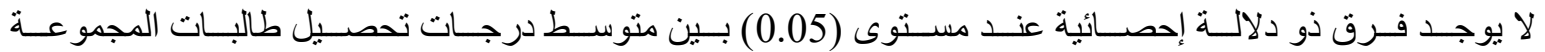

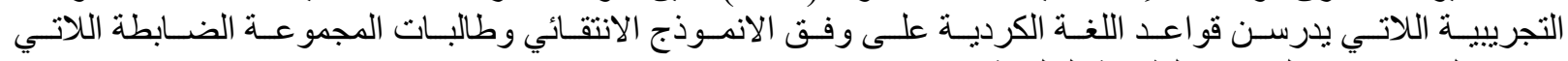
يدرسن المادة نفسها على وفنق الطريقة التقليدية.

$$
\text { يتحدد هذا البحث: - }
$$

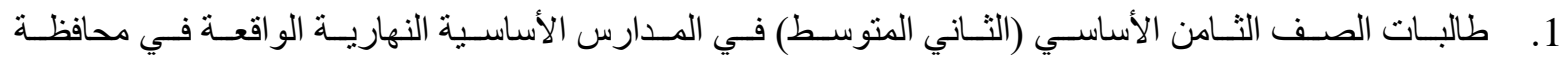

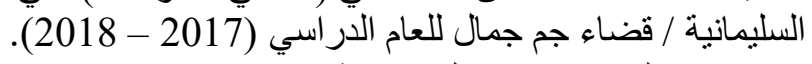

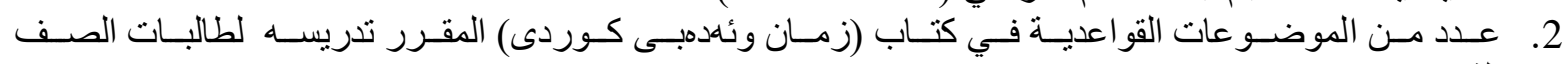

$$
\begin{aligned}
& \text { الثنامن الاساسي. } \\
& \text { 3. الفصل الأول من العام الدراسي (2017 - 2018). }
\end{aligned}
$$




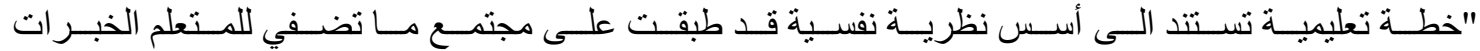

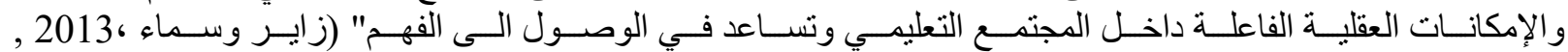

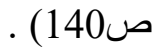

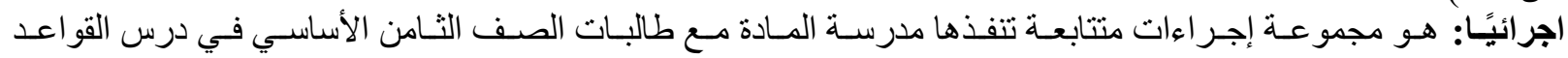

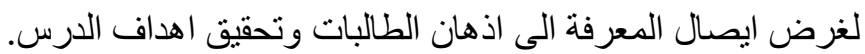

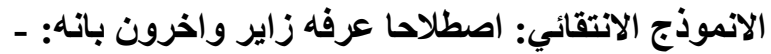

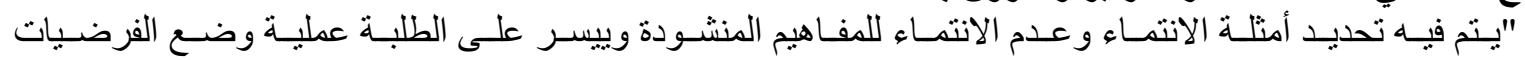

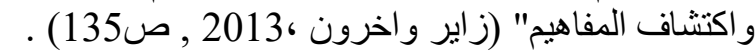

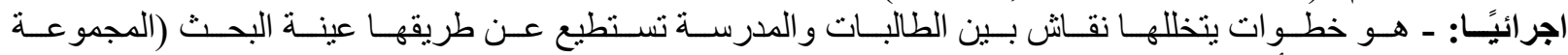

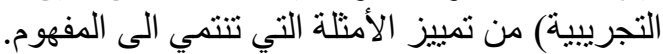

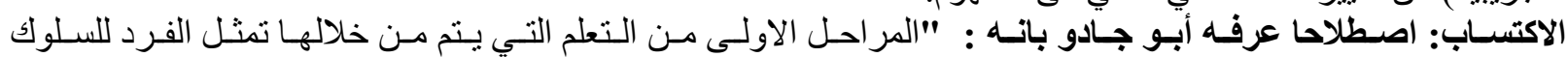

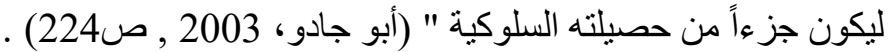
اجرائيًا: - الئزء

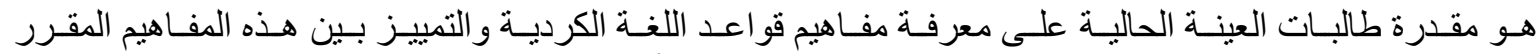

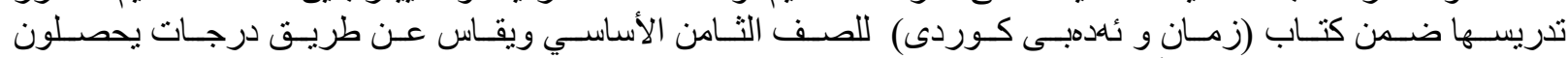

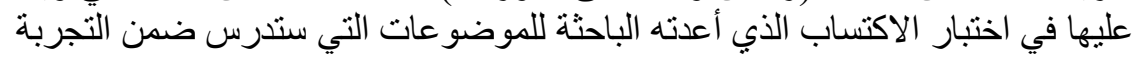
المفهوم: اصطلاحا عرفه الخو الدة باتهه: -

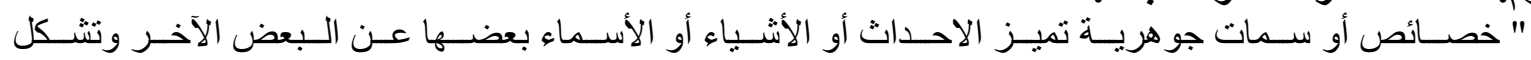

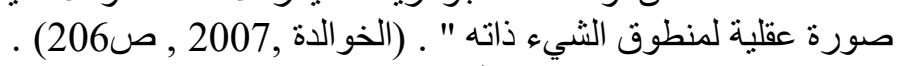

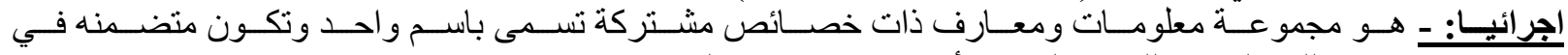

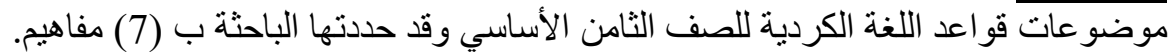

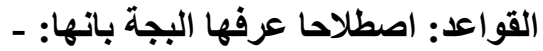

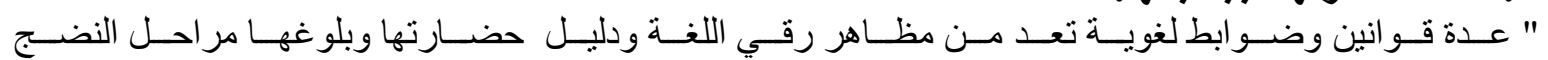

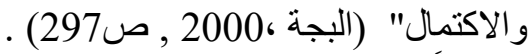

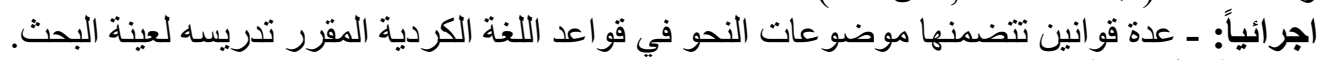

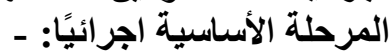

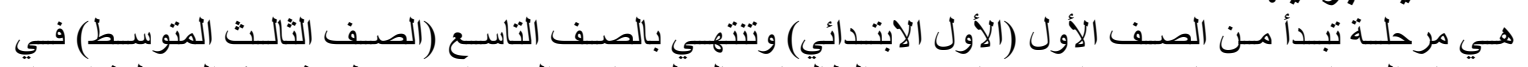

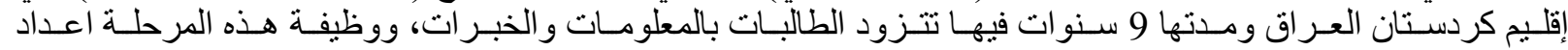
الطالبات لمرحلة دراسية اعلى هي المرحلة الإعدادية.

\section{أولاً: جوانب نظرية

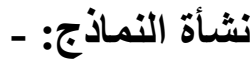

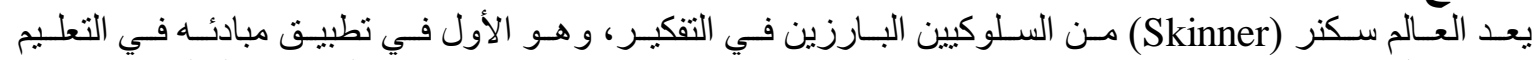

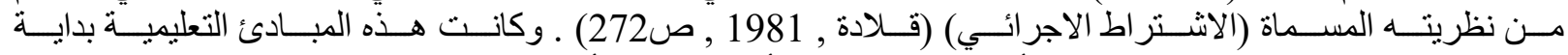

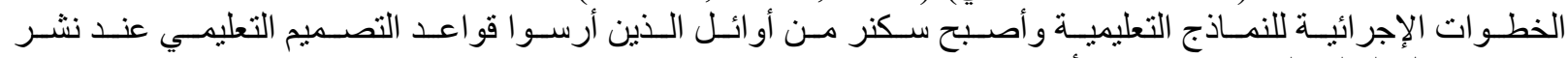

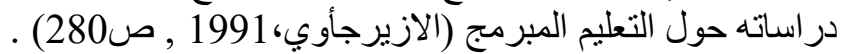

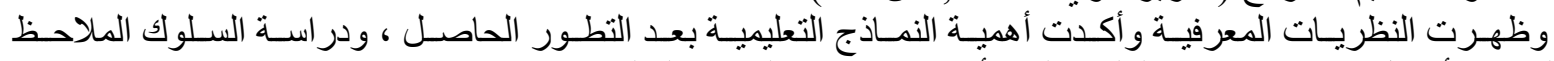
للمتعلم ويعد أوزبل (Ausbel) من العلماء الذين أسهمو ا في بناء النماذج النعان التعليمية.

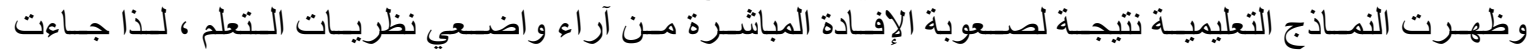

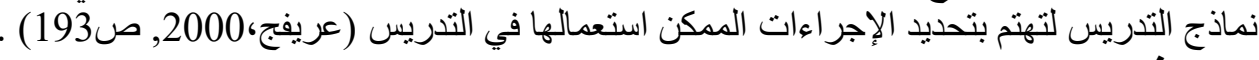
الانموذج الانتقائي

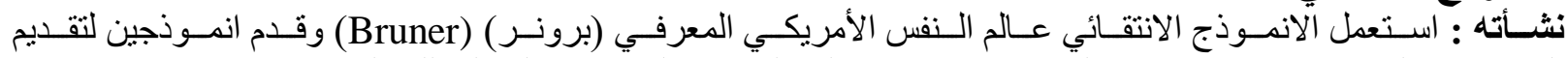

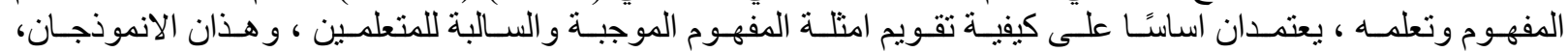

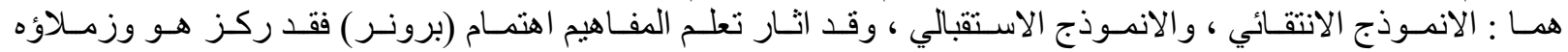

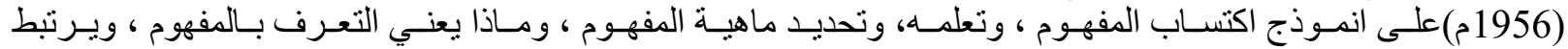
تعلم المفهوم مع عملية التفكير التي اطلق عليها (برونر) التصنيف (Bruner,1965,P:55). 


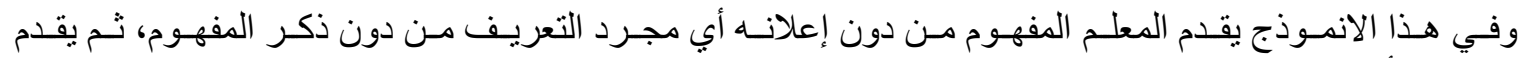

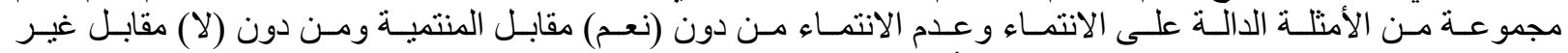

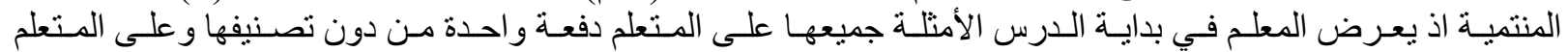

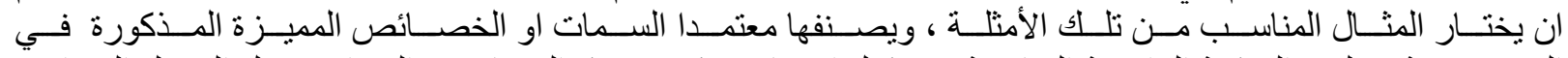

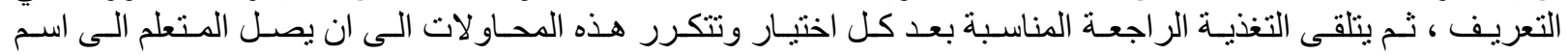

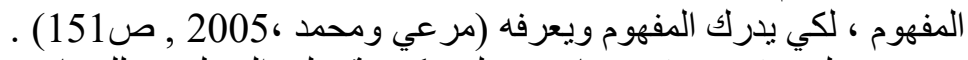

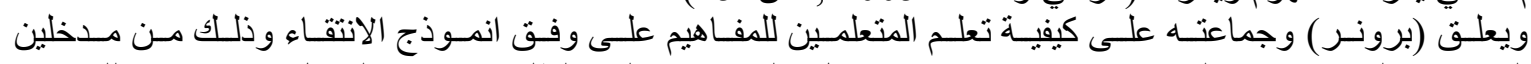

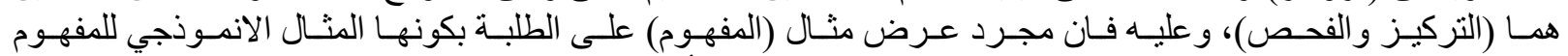

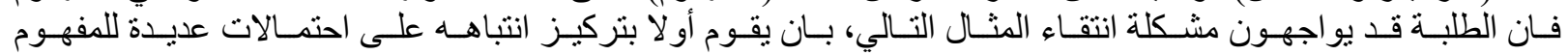

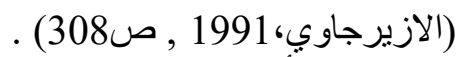

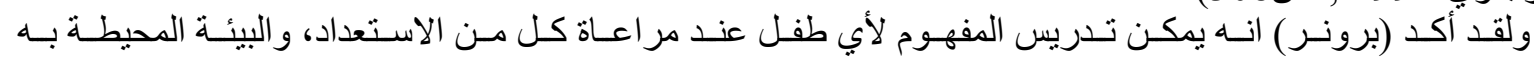

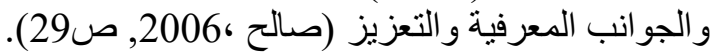

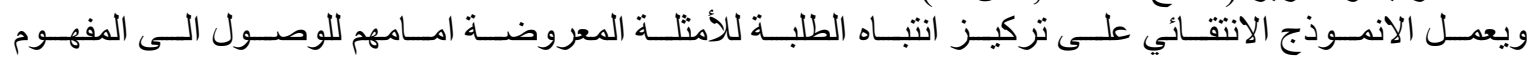

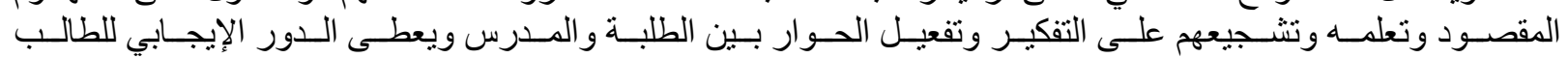

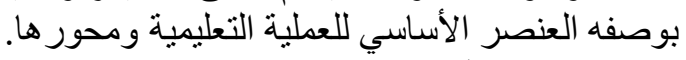

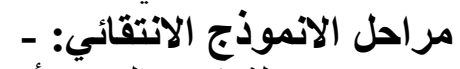

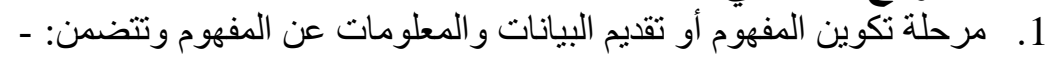
تقديم المدرس امثلة غير مصنفة الى إيجابية أو سلبية.

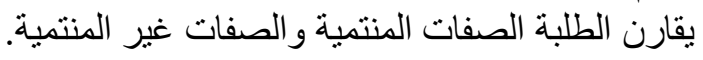

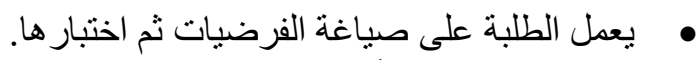

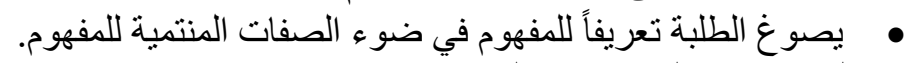

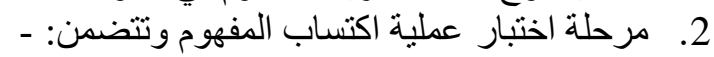

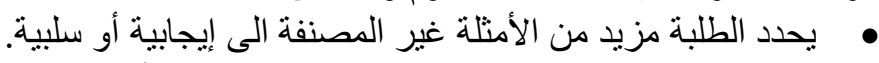

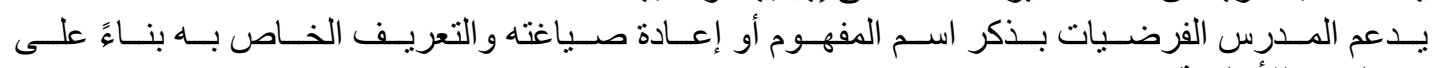
خصائصسه الأساسية.

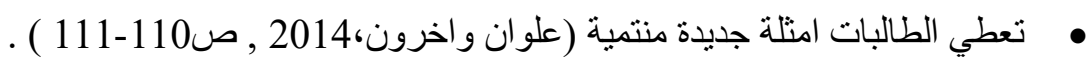

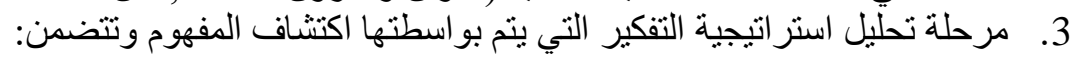
يصف الطلبة الأفكار التي عرضت التئ.

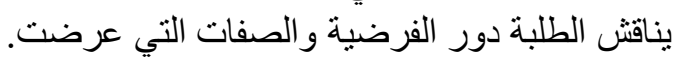
يناقش الطلبة نوع الطرة دور الفرضيات و وعددها.

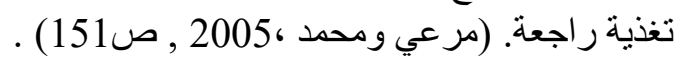

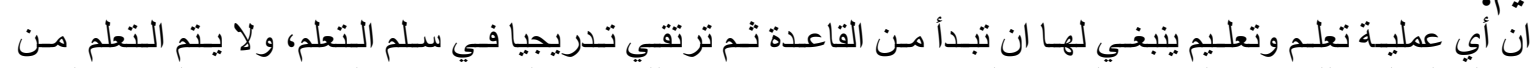

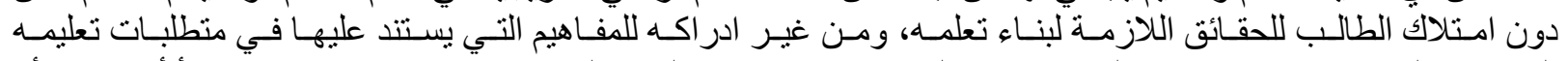

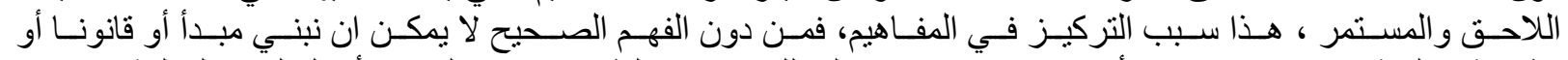

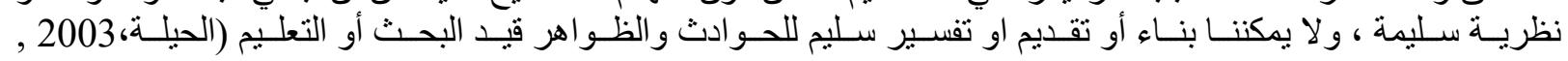

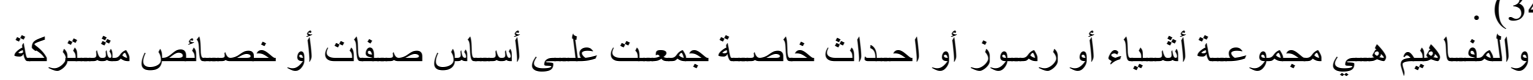

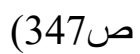

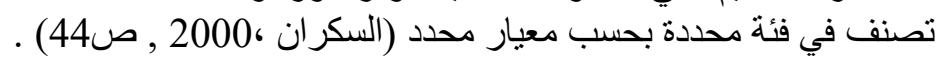

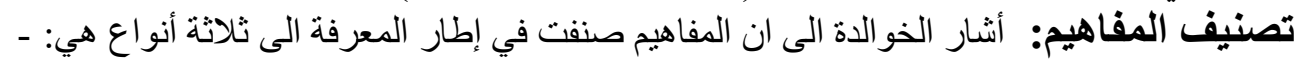
1.

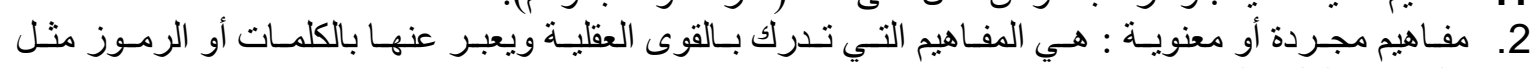
(الحرية و العلم و المروءة معنة).

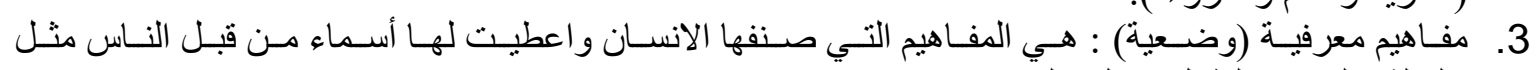

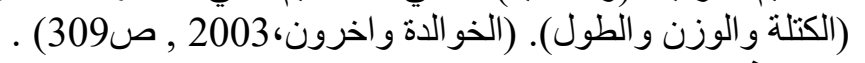




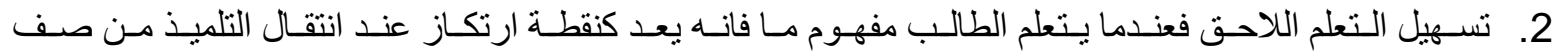

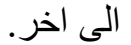

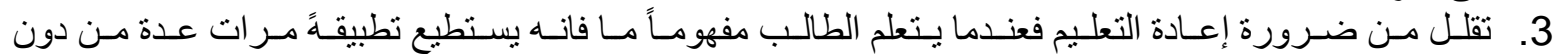
الحاجة الى تعلمه من جديد.

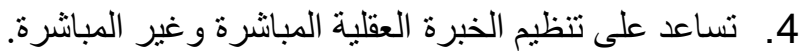

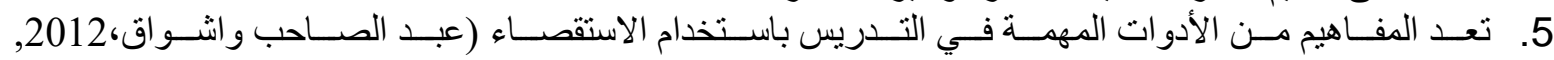

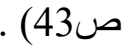
صعوبات تدريس القواعد النحوية:

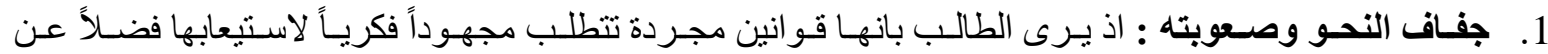

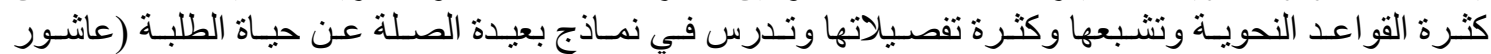

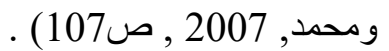

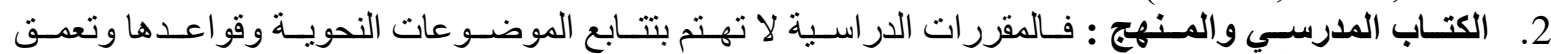

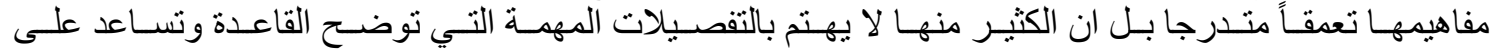

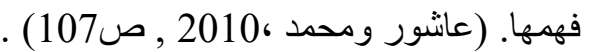

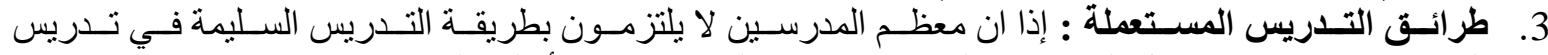

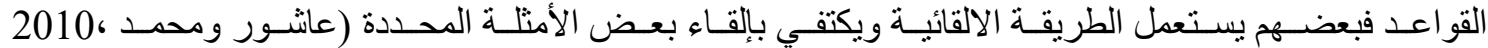

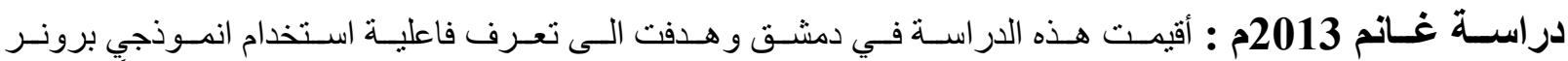

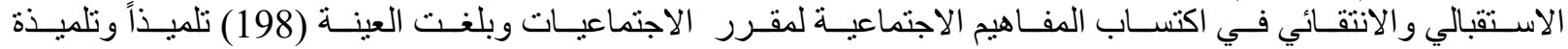
اختار هم الباحث مع أربع مدارس من الحلقة الأولى من التئ التعليم الأساسي.

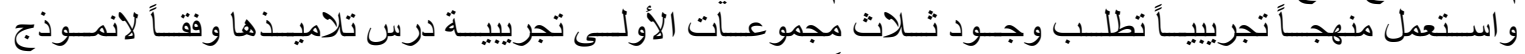

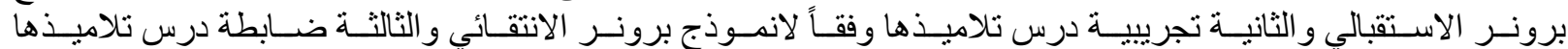

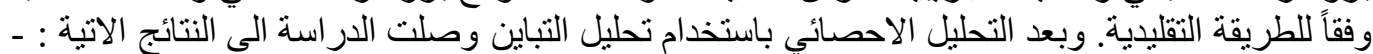

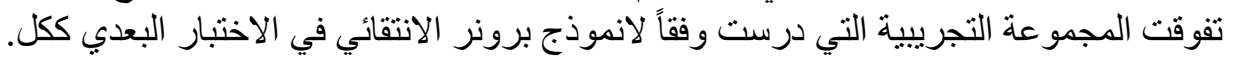

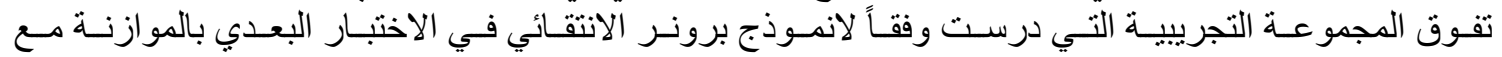

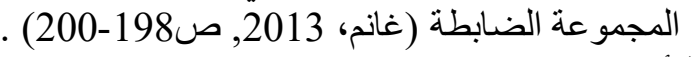

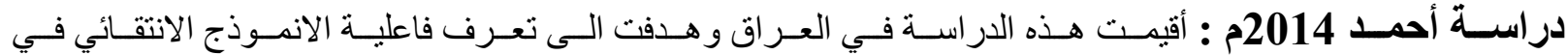

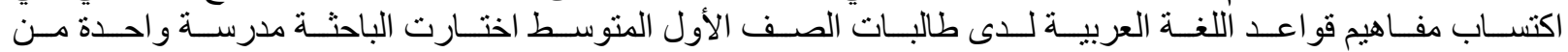

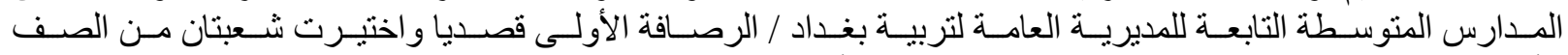

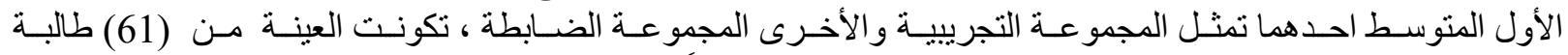

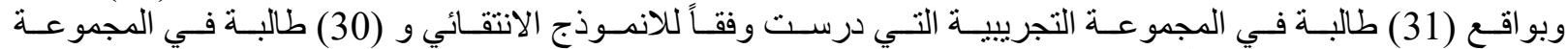

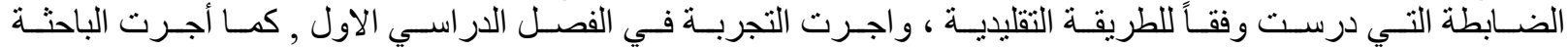

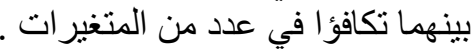

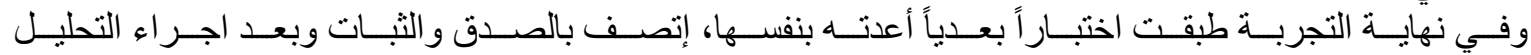

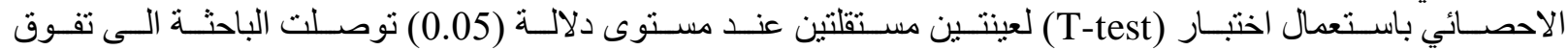

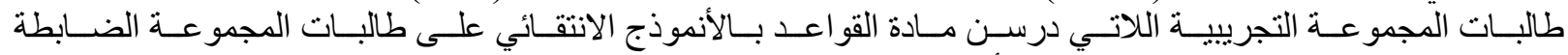

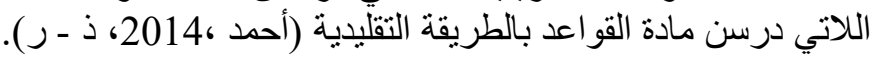

\section{منهجية البحث واجراءاته}

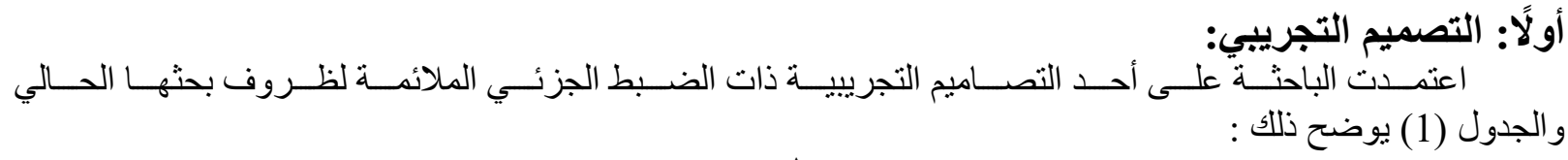

جدول (1)

\begin{tabular}{|c|c|c|c|}
\hline الأداة & المتغير التابع & المتغير المستقل & المجموعة \\
\hline اختبار بعدي للمفاهيم & اكتساب المفاهيم & الانموذج الانتقائي & التجريبية \\
\hline
\end{tabular}




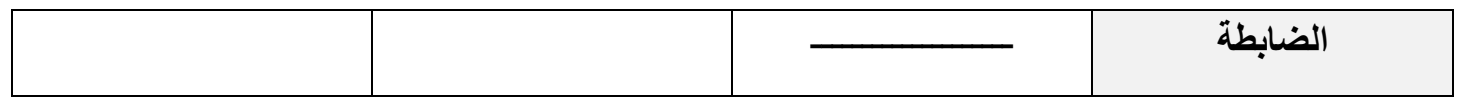

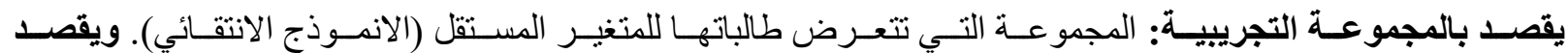

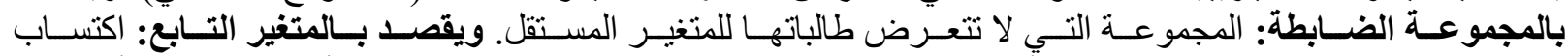

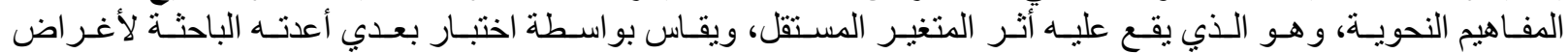

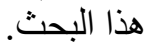

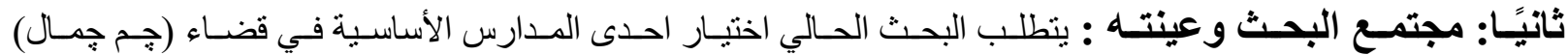

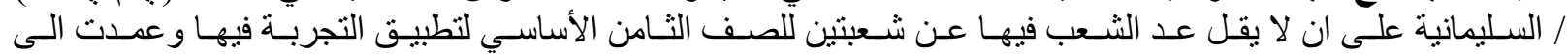

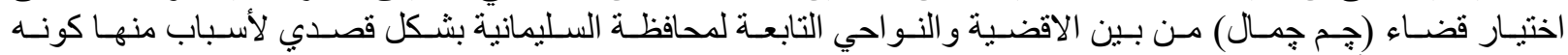

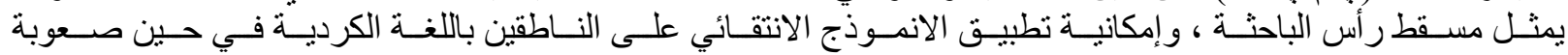
تطبيقه على غير الناطقين بها.

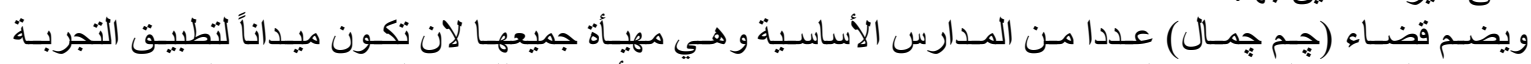

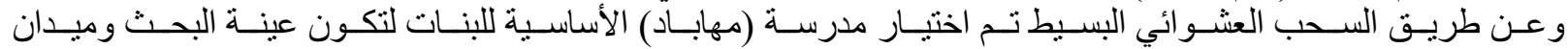

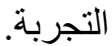

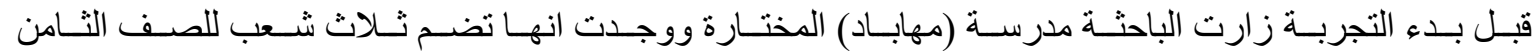

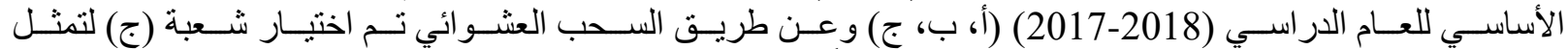

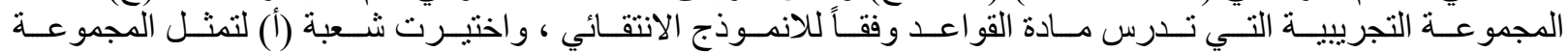
الضابطة الني تدرس القو اعد وفقاً للطريقة التقليدية.

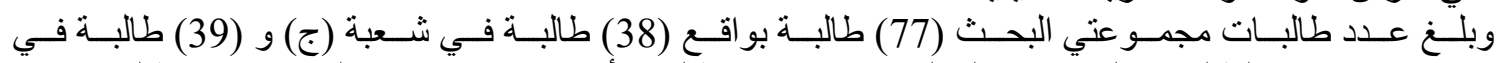

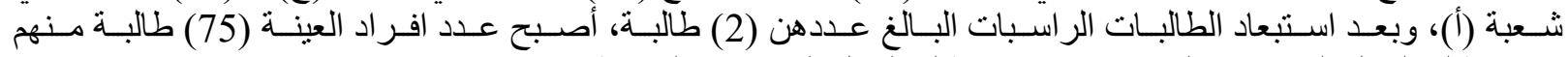

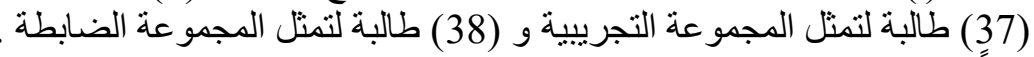

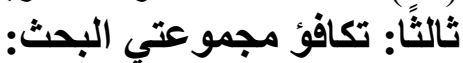

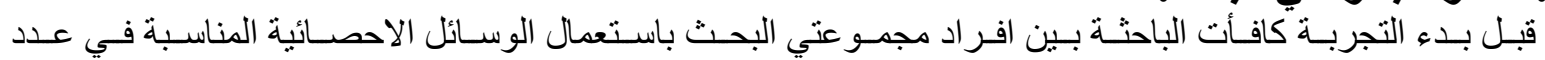

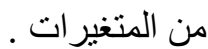

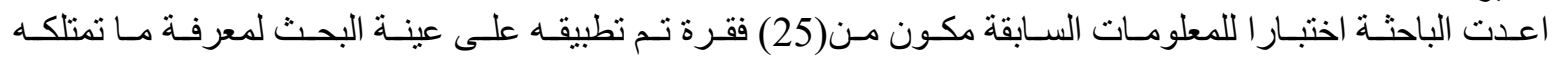

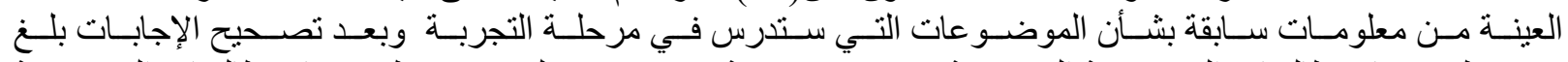

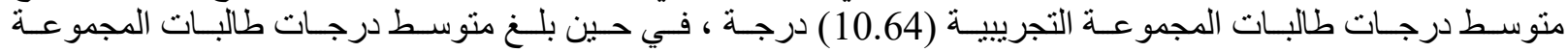

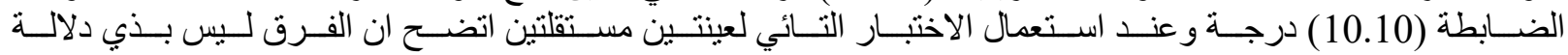

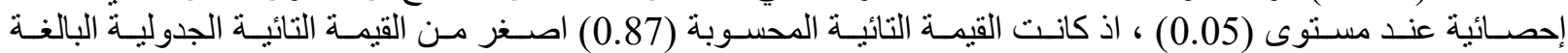
(1.98) وبدرجة حرية (73)و هذا يدل على ان مجمو عتي البحث متكافئتان احصائيا في اختبار المعرفة السابقة.

جدول رقم (2) نتيجة الاختبار التائي لمجموعتي البحث في المعلومات السابقة

\begin{tabular}{|c|c|c|c|c|c|c|c|c|}
\hline \multirow{2}{*}{ مستوى الدلالة } & \multicolumn{2}{|c|}{ القيمة التائية } & \multirow{2}{*}{ الحرية } & \multirow{2}{*}{ التباين } & \multirow{2}{*}{ الانحرياري } & \multirow{2}{*}{ الحستوسي } & \multirow{2}{*}{ حجنم } & \multirow{2}{*}{ المجموعة } \\
\hline & الجدولية & المحسوبة & & & & & & \\
\hline \multirow{2}{*}{ غير دالة } & \multirow{2}{*}{1.98} & \multirow{2}{*}{0.87} & \multirow{2}{*}{73} & 12.74 & 3.57 & 10.64 & 37 & التجريبية \\
\hline & & & & 11.36 & 3.37 & 10.10 & 38 & الضابطة \\
\hline
\end{tabular}

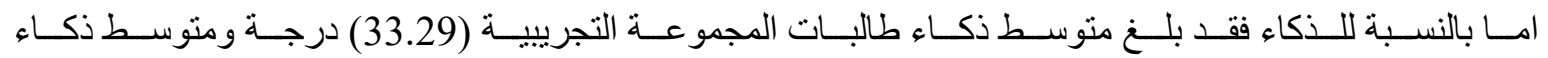

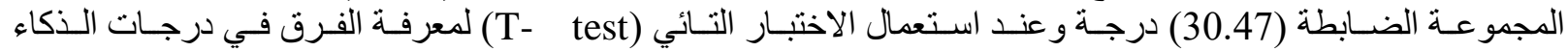

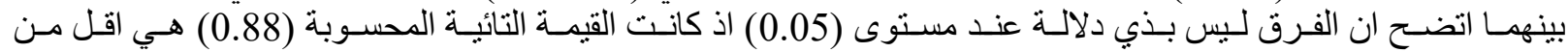

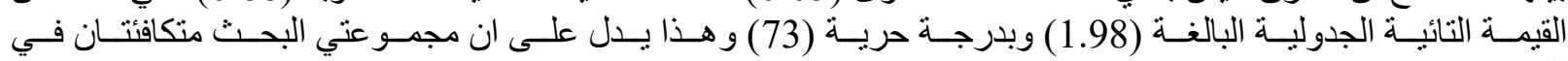

جدول (3) نتيجة الاختبار التائي لمجموعتي البحث في درجة الذكاء

\begin{tabular}{|c|c|c|c|c|c|c|c|}
\hline مستوى & القيمة التائية & درجة & التباين & الانحراف & المتوسط & حجم & المجموعة \\
\hline
\end{tabular}




\begin{tabular}{|c|c|c|c|c|c|c|c|c|}
\hline الدلالة & الجدولية & المحسوبة & الحرية & & المعياري & الحسابي & العينة & \\
\hline غير دالة & \multirow{2}{*}{1.98} & \multirow{2}{*}{0.88} & \multirow{2}{*}{73} & 169.78 & 13.030 & 33.29 & 37 & التجريبية \\
\hline إحصائيا & & & & 191.27 & 13.83 & 30.47 & 38 & الضابطة \\
\hline
\end{tabular}

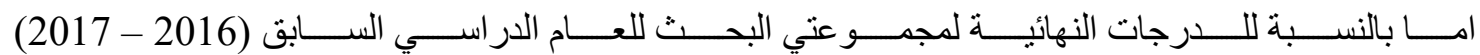

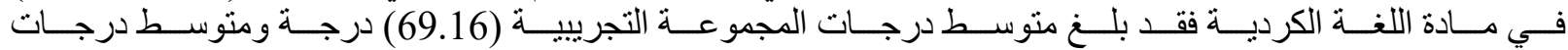

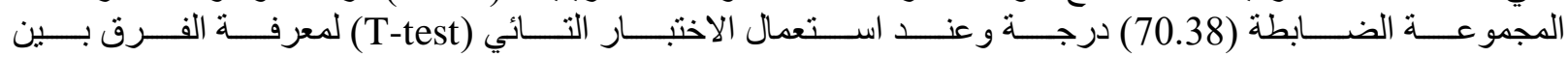

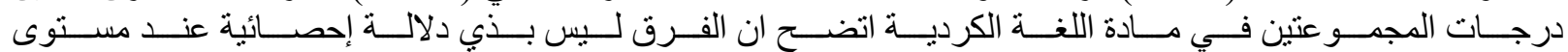

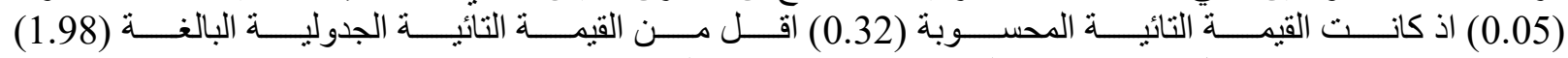

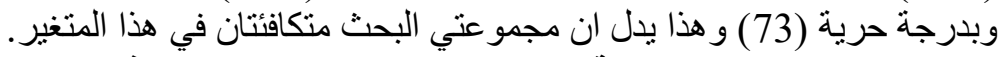
جدول (4) نتيجة الاختبار التائي لمجموعتي البحث في الدرجات النئن النهائية للعام الدراسي السابق

\begin{tabular}{|c|c|c|c|c|c|c|c|c|}
\hline \multirow{2}{*}{ مستوى الدلالة } & \multicolumn{2}{|c|}{ القيمة التائية } & \multirow{2}{*}{ الحرية } & \multirow{2}{*}{ التباين } & \multirow{2}{*}{ الانحرياري } & \multirow{2}{*}{ الحستوسط } & \multirow{2}{*}{ العينْة } & \multirow{2}{*}{ المجموعة } \\
\hline & الجدولية & المحسوبة & & & & & & \\
\hline \multirow{2}{*}{ ليس بذي دلالة } & \multirow{2}{*}{1.98} & \multirow{2}{*}{0.32} & \multirow{2}{*}{73} & 163.84 & 12.80 & 69.16 & 37 & التجريبية \\
\hline & & & & 152.52 & 12.35 & 70.38 & 38 & الضابطة \\
\hline
\end{tabular}

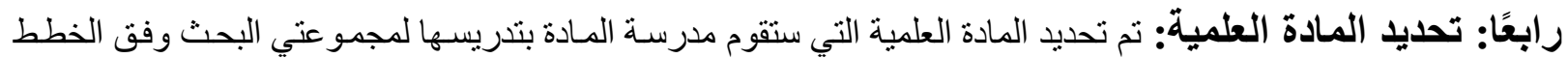

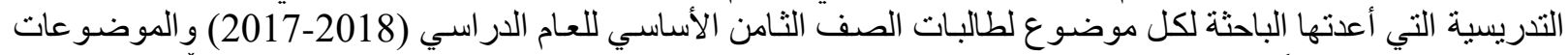

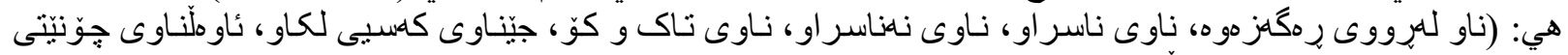

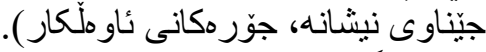

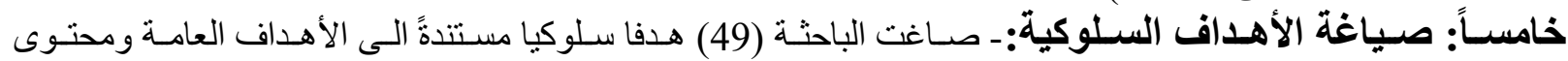

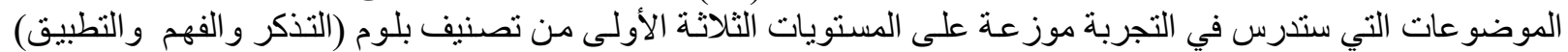

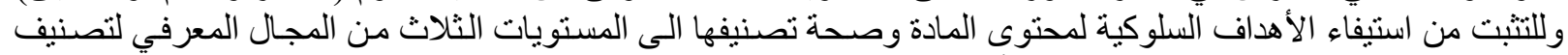

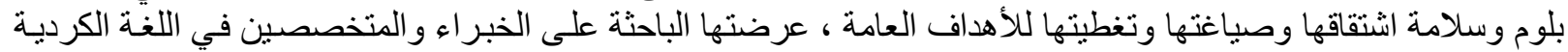

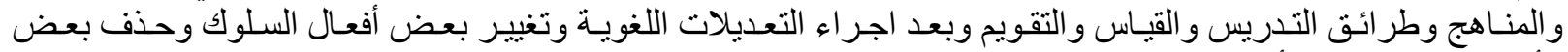

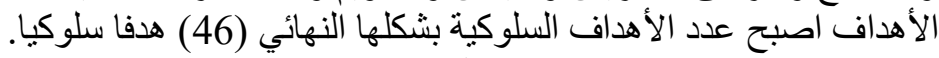

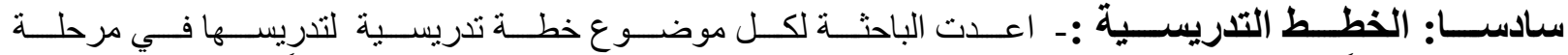

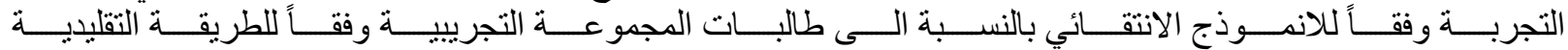

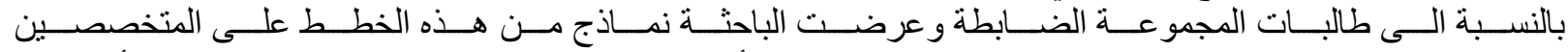

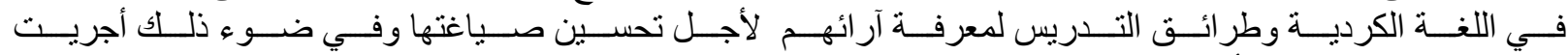

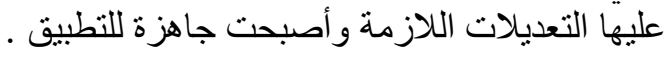

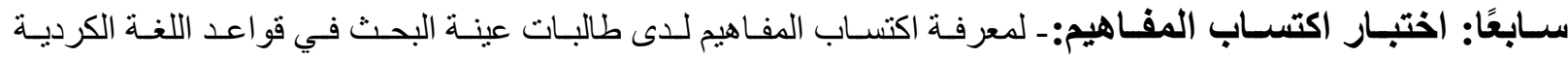

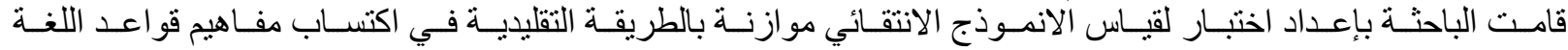
الكردية لدى مجمو عتي البحث

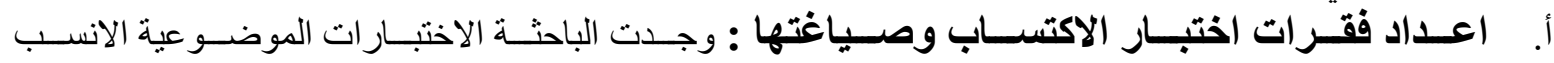

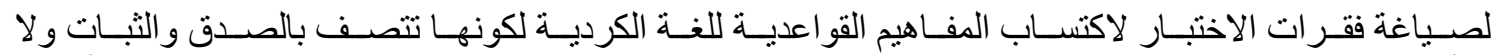

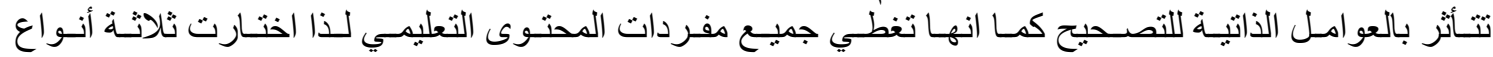

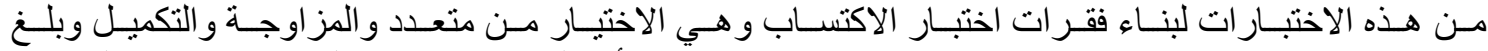

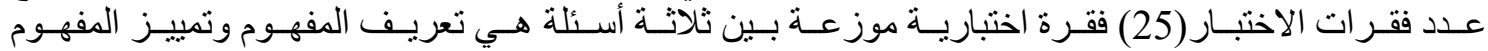

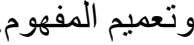

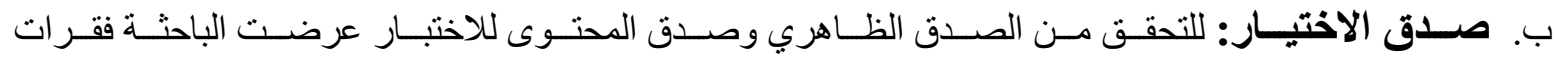

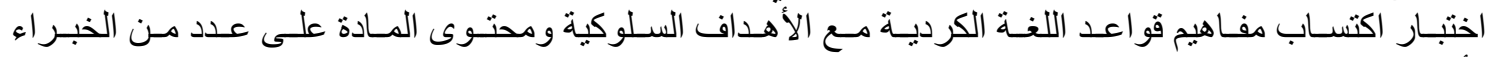

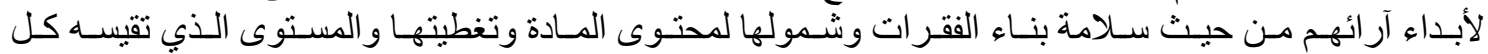
فقرة وقد نالت جميع الفقرات مو افقة الخبر اء بعد اجر اء التعديلات اللازمة. 


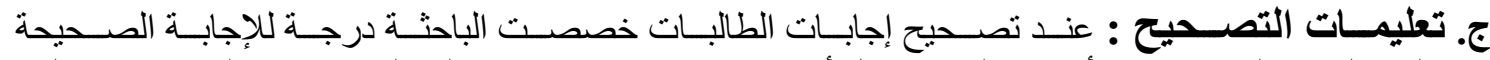

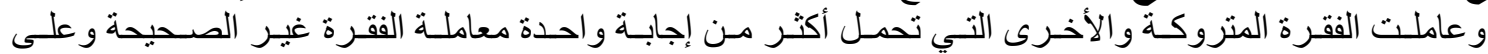

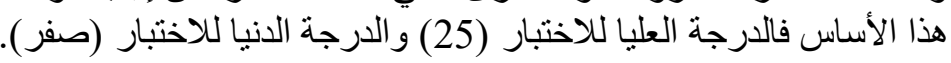

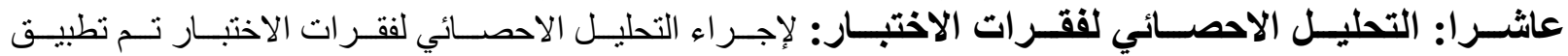

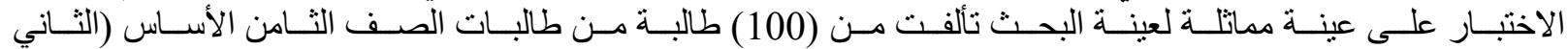

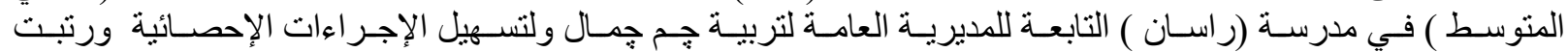

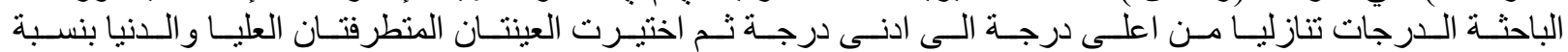

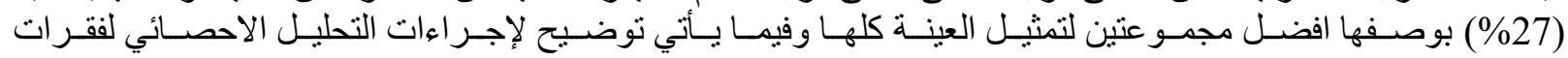

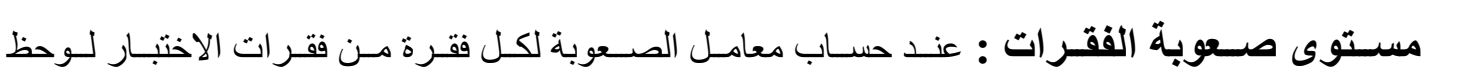
الاختبار:-

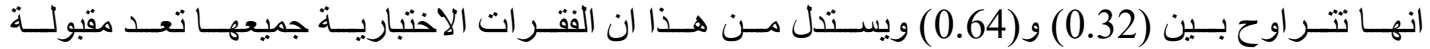

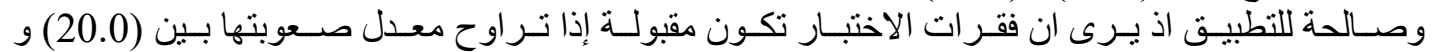

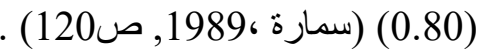

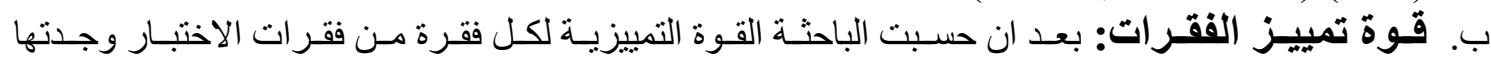

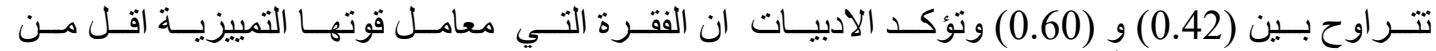

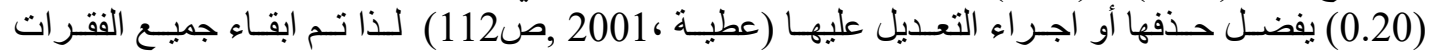
دون حذف أو تعديل .

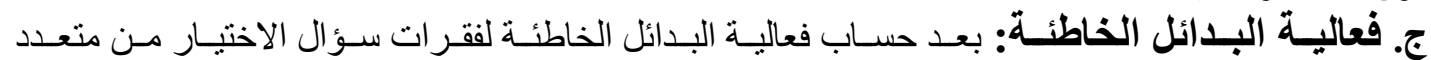

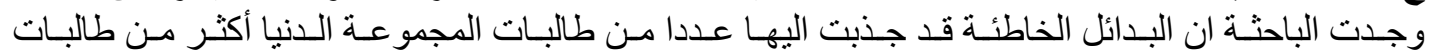
المجموعة العليا لذا ابقت عليها من غير حذف ألت أو تعديل.

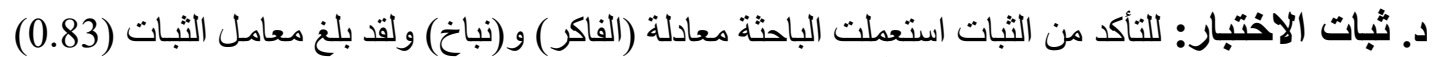

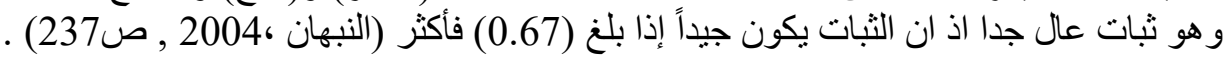

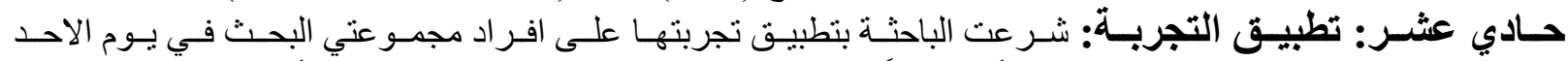

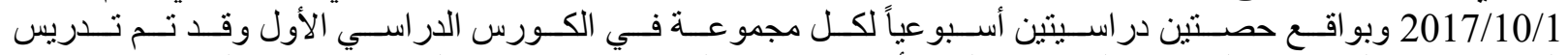

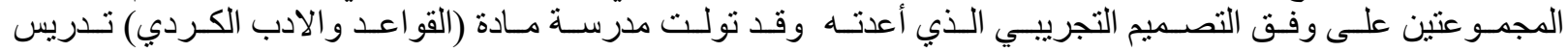

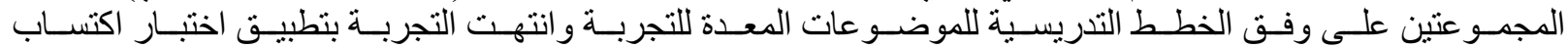
المفاهيم النحوية في يوم الاحد 2017/12/31.

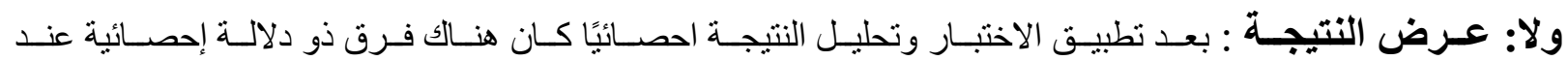

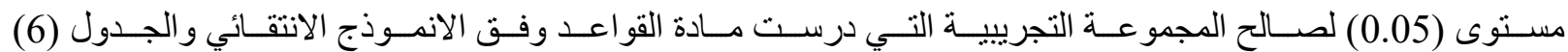
جدول (6) نتيجة الاختبار التائي لمجموعتي البحث في درجات اختبار اكتساب المفاهيم النحوية يوضح ذلك.

\begin{tabular}{|c|c|c|c|c|c|c|c|c|}
\hline \multirow{3}{*}{ 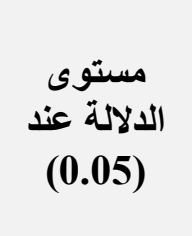 } & \multicolumn{2}{|c|}{ القيمة التائية } & \multirow{2}{*}{ الحرية } & \multirow{2}{*}{ التباين } & \multirow{2}{*}{ المعياري } & \multirow{2}{*}{ الحستبي } & \multirow{2}{*}{ العينة } & \multirow{2}{*}{ المجموعة } \\
\hline & الجدولية & المحسوبة & & & & & & \\
\hline & \multirow{2}{*}{1.98} & \multirow{2}{*}{4.66} & \multirow{2}{*}{73} & 12.04 & 3.47 & 20.51 & 37 & التجريبية \\
\hline دالة احصائيا & & & & 2.52 & 4.53 & 16.31 & 38 & الضابطة \\
\hline
\end{tabular}

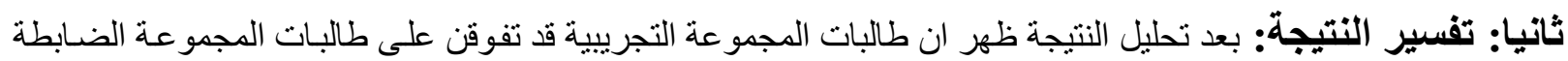

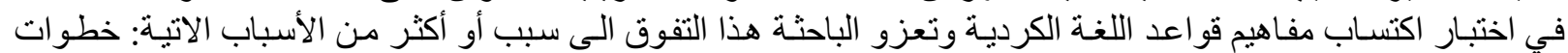

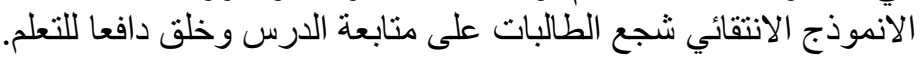

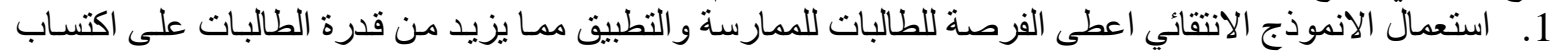

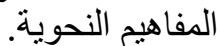
2. ساعد الانموذج الانتقائي على جعل المفاهيم النحوية قابلة للتعلم ويمكن إدر الك الأمثلة الدالة عليها. 


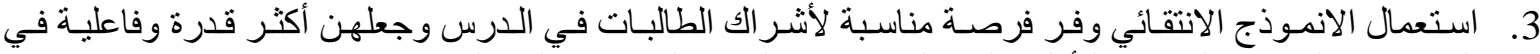

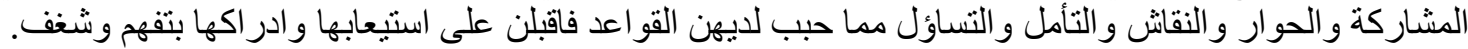

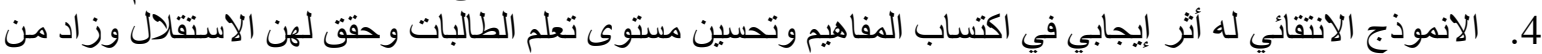

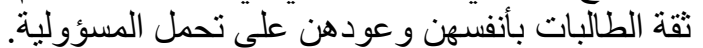
5. ساعد الانموذج الانتقائي الطالبات على استخلاص المفاهيم و الأفكار الرئيسة في المادة المتعلمة.

ثالثا: الاستتتاجات: في ضوء نتائج البحث الحالي استتنجت الباحثة الآتي :

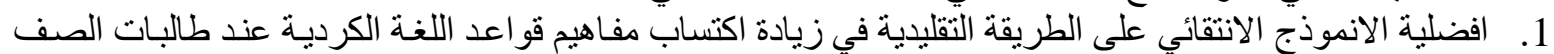
الثامن الأساسي.

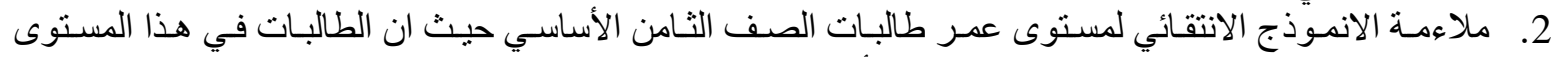

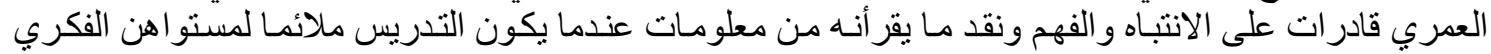

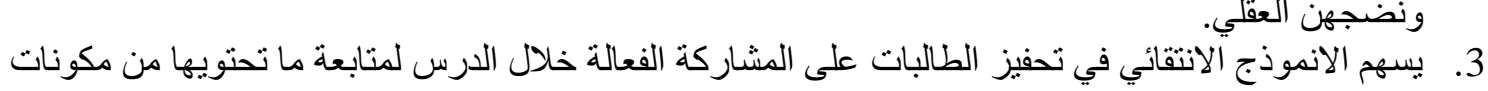

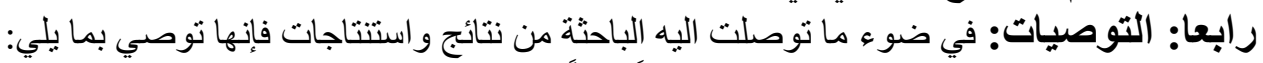

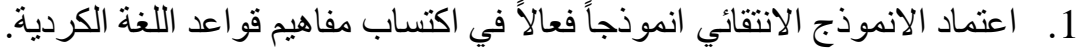

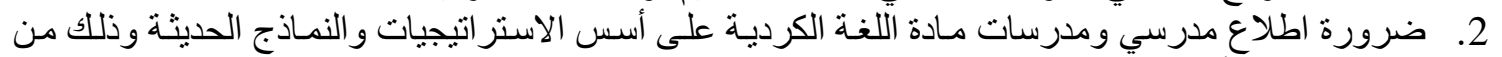
خلال الدورات أو الندو آت التربوية.

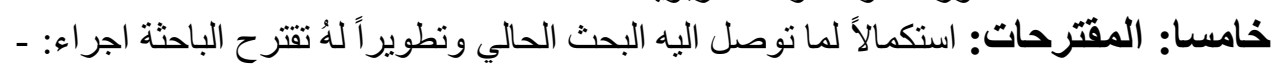
1.

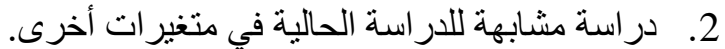
3. در اسة مشابهة للار اسة الحالية في مواد در اسية أخرى.

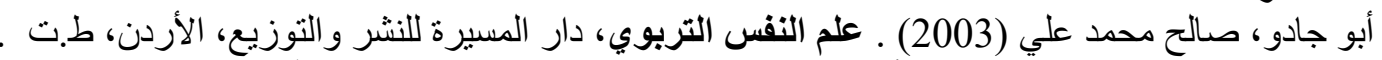

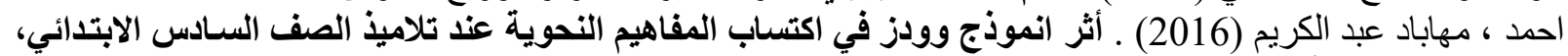

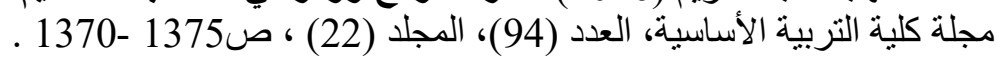

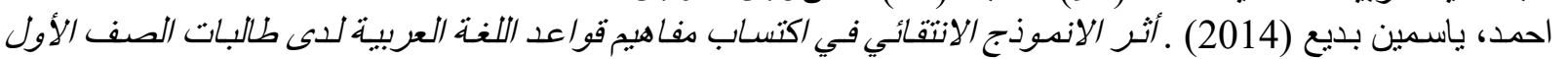

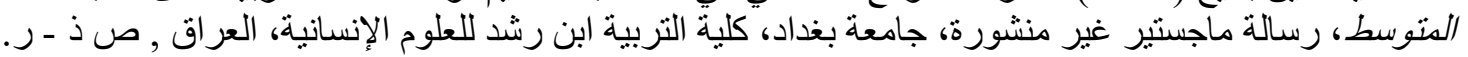

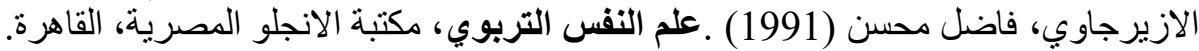

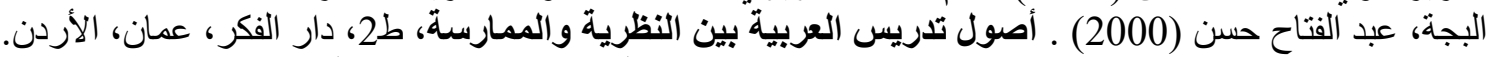

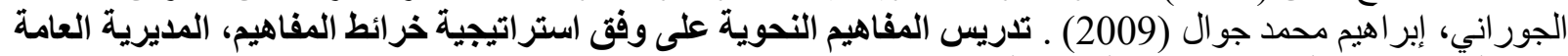
للتربية في محافظة بغداد الرصـافة الثانيـة، مركز البحوث و الدراسـات العربيـة، العدد السـابع، وزارة التربيـة، العراق ،

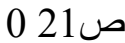

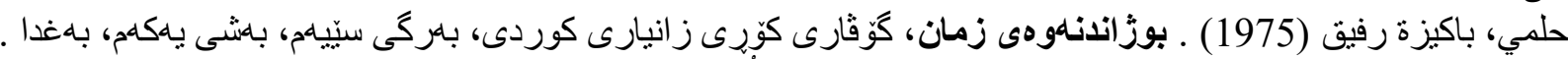

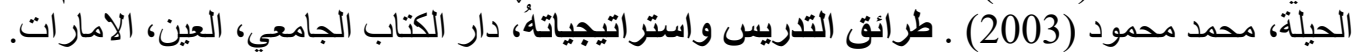

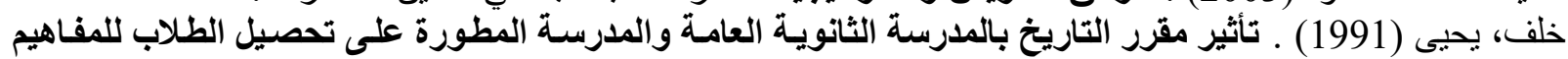

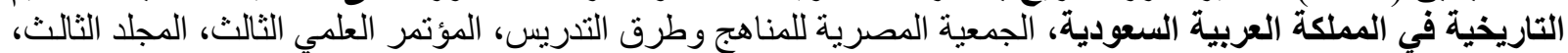

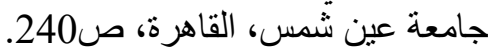

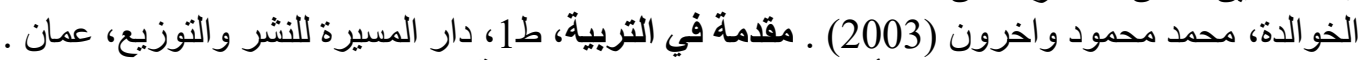

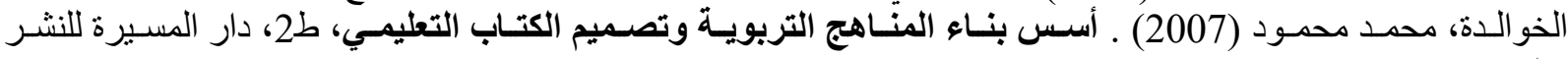
و التوزيع، عمان. الدريج ، محمد (2004) ـ التدريس الهادف من نموذج التدريس بالأهداف الى نموذج التدريس بالكفايات، ط1، دار الكتاب

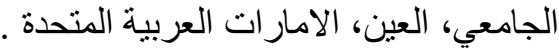

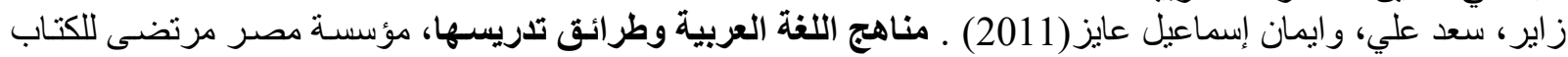

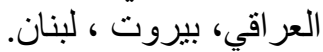

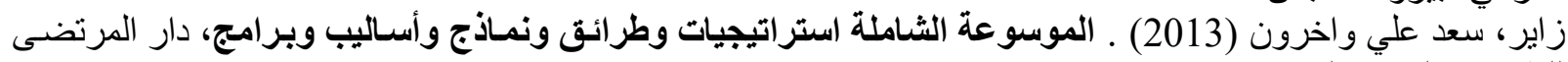
للطباعة و النشر و التوزيع بغداد ـ لخرون 
زايـر، سـعد علي ، وسـماء نركي داخل (2013) ـ اتجاهـات حديثـة في تـريس اللغـة العربيـة وطرائق تدريسـها، دار

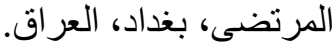

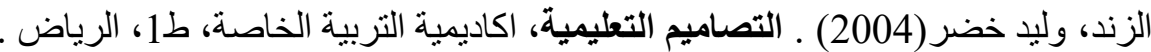

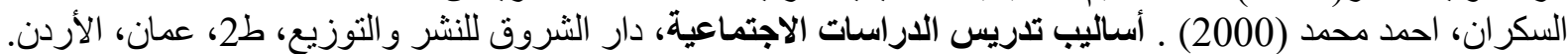

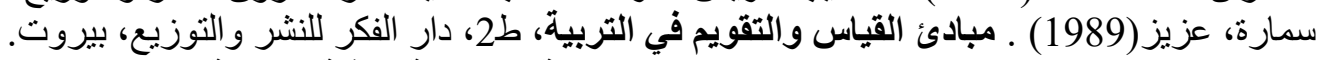

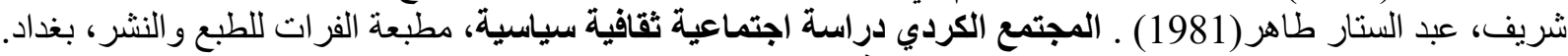

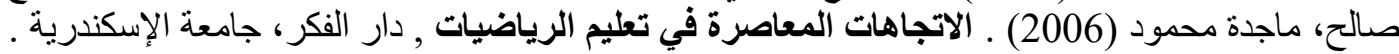

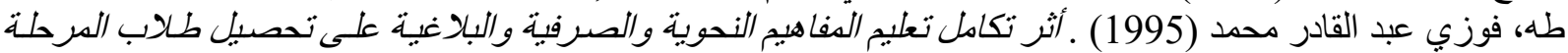

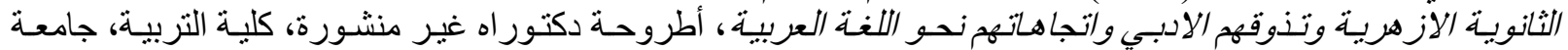

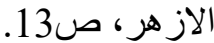
عاشـور، راتب قاسـم، ومحمد فؤ اد الحوامدة (2007) ـ أسـاليب تلدريس اللفـة العربيـة بين النظريـة والتطبيق، ط2، دار

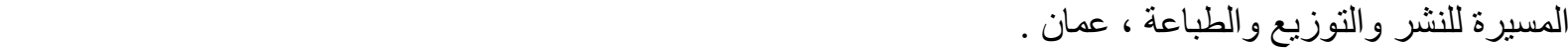

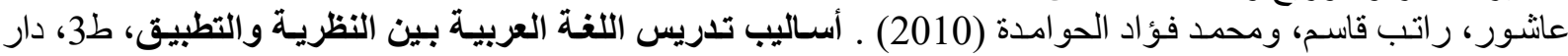

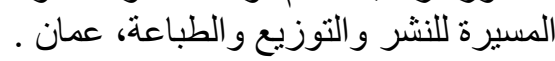

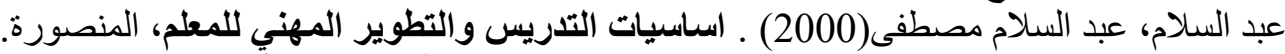

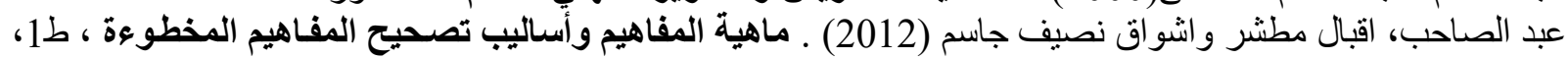

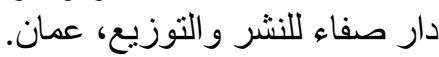

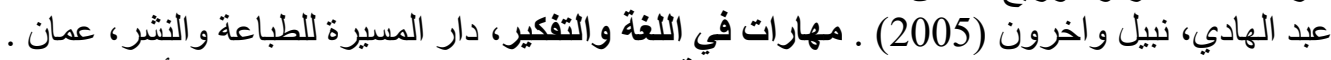

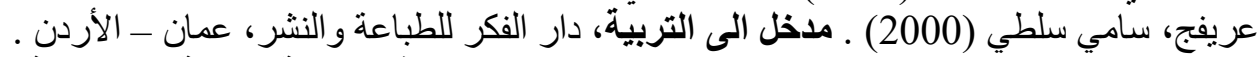
عطية، السيد عبد الحميد (2001) ـ التحليل الاحصائي وتطبيقاته في دراسة الخئة الخدمة الاجتماعية، المكتب الجامعي الحديث، الإسكندرية . الإنية

عطية، محسن علي (2010) ـ أسس التربية الحديثة ونظم التعليم، دار المناهج للنشر و التوزيع، عمان، الأردن.

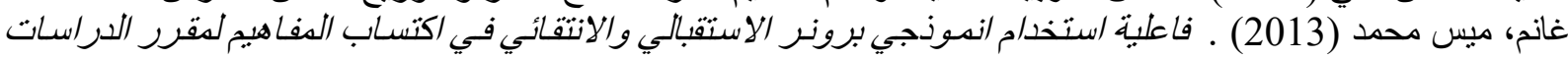

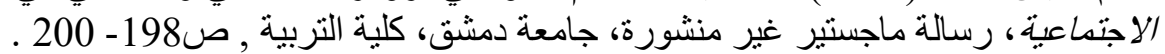

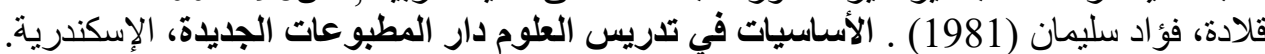

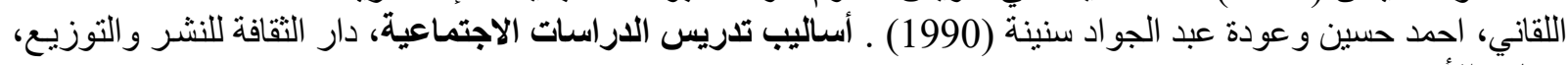

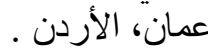
مدكور، علي احمد (2000 ) ـ ـ تدريس فنون اللغة العربية، ط1، دار الفكر العربي، القاهرة .

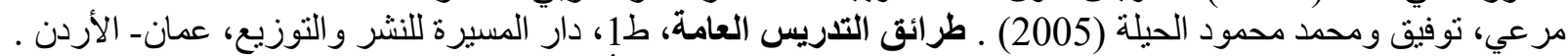

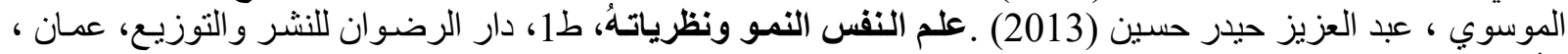

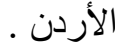

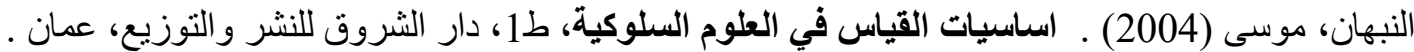

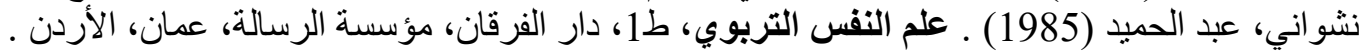

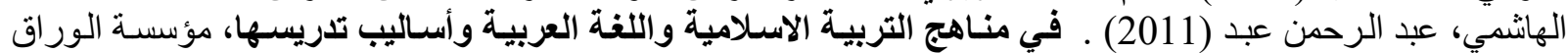

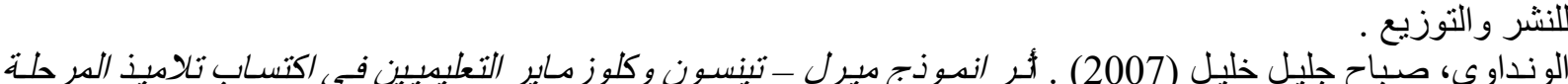

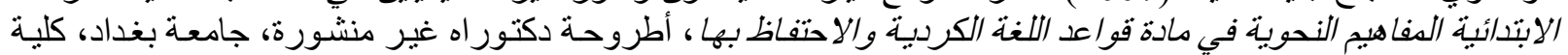

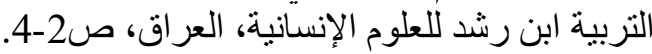




\section{References}

Abu Jado, Salih Mohammed Ali (2003), Educational Psychology, Jordan: Dar Al- Masira for Publication and Distribution.

Ahmed, Mahabad Abdel Karim (2016), The effect of Woods model in Acquiring the grammatical Concepts among Sixth-grade- Primary Pupils, Journal of College of Basic Education, Issue (94), Vol. (22), P:1357-1370.

Ahmed Yasmin Badeah (2014), The effect of the eclectic model in acquiring the concepts of Arabic Grammar among the first intermediate School Students, Unpublished Master's thesis - University of Baghdad, College of Educational, Ibn Rushd for Human Sciences,P:r.

Al- Azzerjawy, Fadhel Mohsen (1991), Educational Psychology, Anglo- Egyptian Library, Cairo.

Ausubel (1962) . D.P organizer, General back ground and antecedent learning. journal of education psychology, no, (3).

Al- Bajah, Abdel Fatah Hassan (2000), Principles of teaching Arabic between the theory and practice, Edition (2), DAR, AL- FAKR, Amman, Jordan.

Bruner, J.S \& et (1965) . et A study of thinking. john Wiley \& sons new York .

Al- Jourany, Ibtahim Mohammed Jawal (2009), Teaching the Grammatical Concepts according to Map Concepts Strategy, The General Directorate of Education, Baghdad Al- Rusafa the Second, Center of Arab researches and studies, Ministry of Education, Iraq, P:21.

Al- Hilah, Mohammed Mahmood (2003), Methods of Teaching and its Strategy, Dar AlKitab Al- Jamea, Al- Ain EAU.

Khalaf, Yahya (1991), the effect of History textbook in acquiring students the Historical concepts in Kingdom of Saudi Arabia, The Egyptian Association of Curriculum and methods of teaching the third Scientific Conference, Vil. (3), University of Ain Shams, Cairo, P:240.

Al- Khawal DAH, Mohammed Mahmood (2003), Introduction to Education, Edition, (1) Dar- Al- Masirah for Publication and Distribution Amman.

(2007), Fundamentals of setting up Educational

Curriculum and designing the Educational Textbook, Edition , (2) Dar- Al- Masira for Publication and Distribution, Amman.

Al- Dureij, Mohammed (2004), The Constructive Teaching, Out of Teaching, Aimed Model into Teaching, Competence, Teaching Model, Edition , (1) DAR Al- Kitab Al- Jamea, Al- AIN, UAE.

Zaer, Saad Ali (2011), Curriculum of Arabic Language and its Methods of Teaching, Misr Foundation Beirut, Lebanon.

(2013), The Comprehensive Encyclopedia of Strategies and

Methods of Teaching, Dar Al- Murtadha for Publication and Distribution, Baghdad.

(2013), New Trends in Teaching Arabic Language and

Methods of Teaching, Dar Al- Murtadha for Publication and Distribution, Baghdad.

Al- Zanad, Walid Khudhur, (2004), The Educational Designs, Private Al- Riyadh Academy of Education, Edition (1).

Al- Sakran, Ahmed Mohammed (2000), Methods of teaching THE SOCIAL STUDIES, Dar Al- Shurooq for Publication and Distribution, Edition (2), Amman.

Samarah, Aziz (1989), Principles of measurement and Evaluation in Education, Edition (2),

Dar- Al- Fakr for publication and Distribution, Beirut. 
Shareef, Abdel Sattat Taher (1981), The Kurdish Community Asocial, Cultural and Political Study, Al- Furat Publishing House, Baghdad.

Saleh, Majeda Mahmood (2006), The Contemporary Trends in Teaching Mathematics. Dar- Al- Fakr, University of Al- Askandiriyah.

Thah, Fawzi Abdel Qadir Mohammed (1995), The effect of teaching the grammatical, morphological and Rhetorical concepts on Achievement of the secondary school students towards Arabic Language. Unpublished Dissertation College of Education, AlAzhar University, P:13.

Ashur, Rateb Qasem and Mohammed Found Al- Hawamdah (2007), Methods of teaching Arabic Language between theory and practice, Dar Al- Masirah for Publication and Distribution, Amman.

(2010), Methods of teaching Arabic Language between

theory and practice, Edition (3), Dar Al- Masirah for Publication and Distribution, Amman.

Abdel Salam, Abdel Salam Mustafa (2000), Fundamentals of Teaching and Vocational Development of Teachers, Al- Mansoorah.

Abdel Saheb, Iqbal Mutasher and Ishwaq Nuseif Jassem (2012), The essential nature of concepts and Methods of Correcting erroneous concepts, Edition (1), Dar Safa for Publication and Distribution, Amman.

Abdel Hadi, Nabil, et.al. (2005), Skills in Language and Thinking, Dar Al- Masirah for Publication and Distribution, Amman.

Oreifaj, Sami Salti (2000), An Introduction to Education, Dar Al- Fakr for Publication and Distribution, Amman.

Attiyah, Al- Sayyed Abdel Hameed (2001), The Statistical Analysis and its applications in Studying the Social service, The modern office, AL- Askandariya University.

Ghanem, Mays Mohammed (2013), The effectiveness of using Broner's two models of Receptive and Eclectic in Acquiring the concepts of the textbooks of the social studies, unpublished Master's thesis, University of Damascus College of Education, p:198-200.

Qelada, Foud Sulaiman (1981), The Basics of teaching sciences, The modern Publishing House, Al- Askandariyah.

Al- Laqny, Ahmed Hussein and Auda Abdel Jawad Sanina (1990), Methods of teaching the social studies, Dar- Al- Thaqafa for Publication and Distribution, Amman.

Madkoor, Ali Ahmed (2000), Teaching The Arabic Language Arts, Dar- Al- Fakr Al- Araby, Cairo.

Marea, Tawfiq and Mohammed Mahmood Al- Hila (2005), Method of General Teaching, Edition, (1) Dar Al- Masira for Publication and Distribution, Amman, Jordan.

Al- Mawsawy, Abdel Aziz Hayder Hussein (2013), Developmental Psychological and its theories Edition, (1) Dar Al- Radhwan for Publication and Distribution, Amman, Jordan.

Al- Nabhan, Mosa (2004), Basics of Measurement in the behaviorist sciences Edition ,(1) Dar Al- Shurooq for Publication and Distribution Amman.

Nasheany, Abdel Hameed (1985), The Educational Psychology, Edition (1), Dar Al- Furqan, Al- Resalah Organization, Amman, Jordan.

Al- Hashimy, Abdel Rehman Abed (2011), Methods of Islamic Education and Arabic Language and Methods of teaching, Al- Waraq Organization for Publication and Distribution.

Al- Wandawy, Sabah Jalil Khalil (2007), The effect of Models of Mirl, Tennyson and Clausmayer in Achievement of the grammatical concepts in the Kurdish Language among the primary pupils, Unpublished Doctorate's dissertation, University of Baghdad, College of Education Ibn Rusd for Human Sciences, P: 2-4. 


\section{الملحق}

\section{الاختبار بصيغتة النهائية}

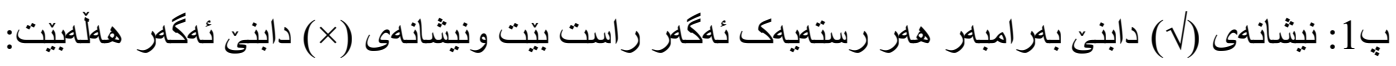

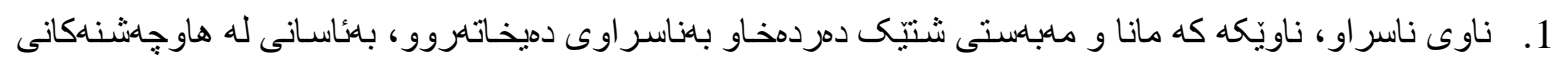

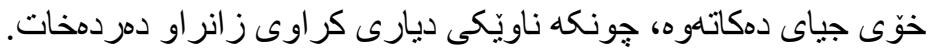

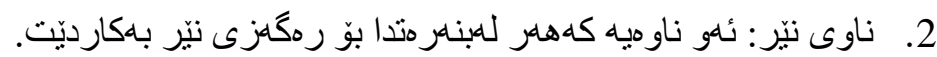

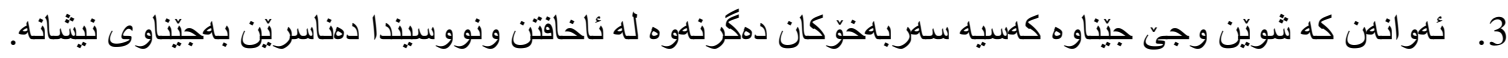

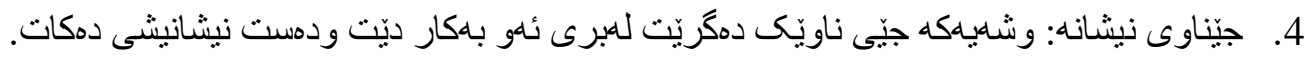

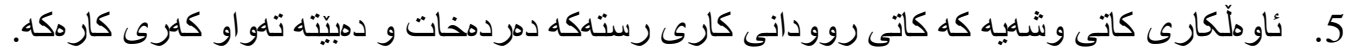

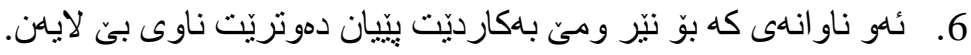
7.

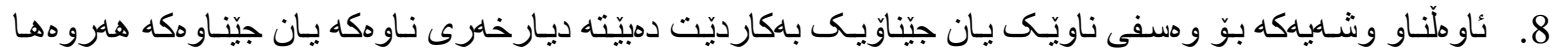

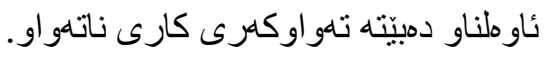




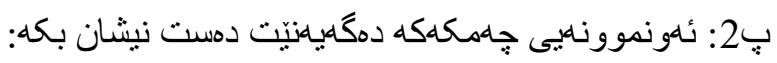

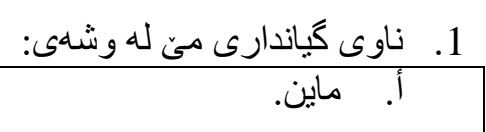

2.

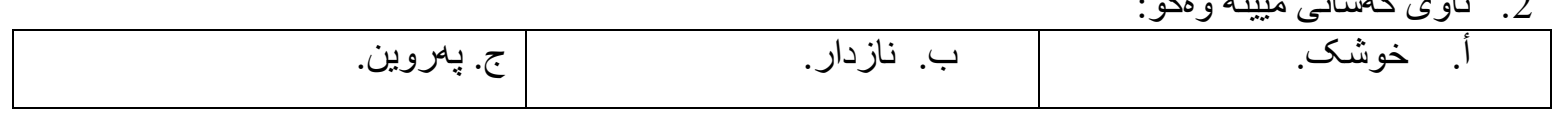

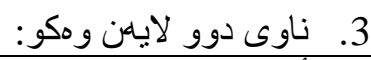

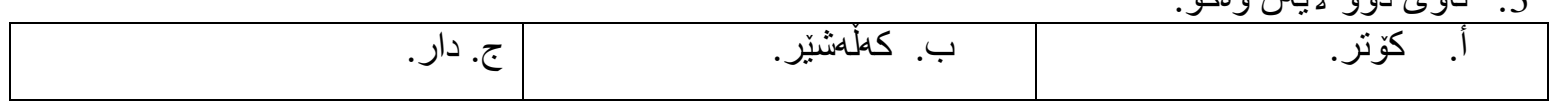

\begin{tabular}{|c|c|c|}
\hline & & 4. نيشانهى نهاناسر اوى ئهمانهن: \\
\hline ج. (يّك، 0ك، ىّ). & ب. (كه، يّك، مكه). & 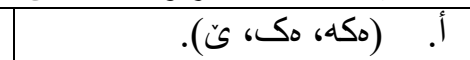 \\
\hline
\end{tabular}

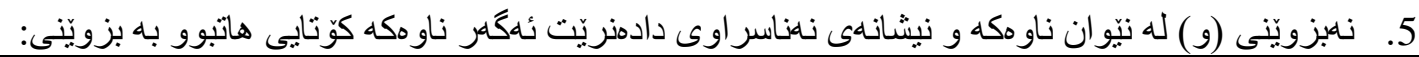

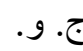

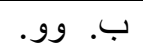

أ. أ. نَو.

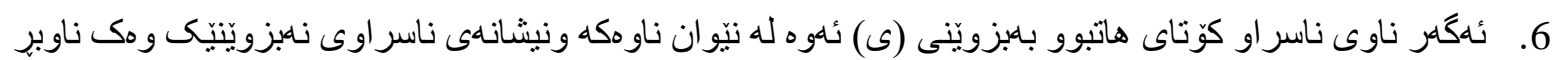

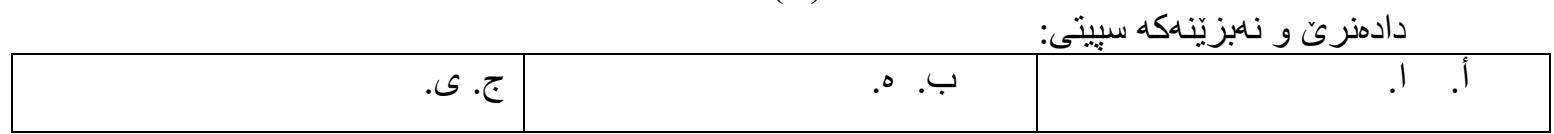

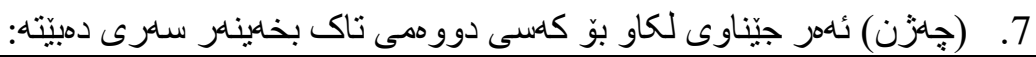
أ. جا. جازنى.

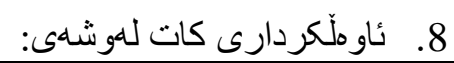

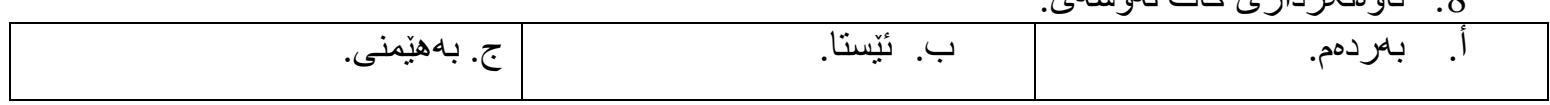

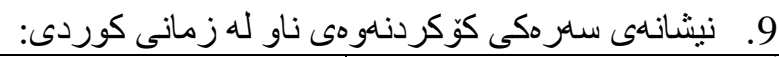

ج. ن بن. بأب.

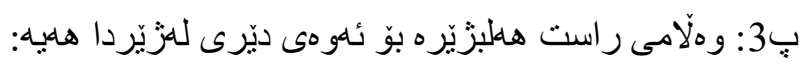

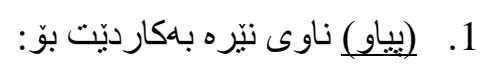

\begin{tabular}{|c|c|c|}
\hline ج. ناوى بِيشاهى يِياو ان. & ب. ن. ناوى كلسانى نَّر. & أ. ناوى تاييهت باكوريان. \\
\hline
\end{tabular}




\begin{tabular}{|r|r|r|}
\hline أ. & ار. \\
\hline
\end{tabular}

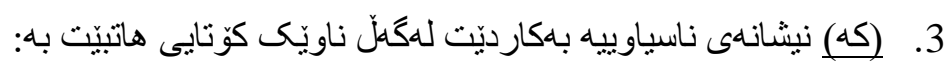

\begin{tabular}{|c|c|c|}
\hline ج. هلردوو بزويَن ونهبزويَن. & ب. ـهبزوين. & أ. بزويَن. \\
\hline
\end{tabular}

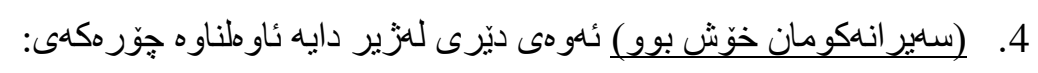

\begin{tabular}{|c|c|c|}
\hline ج. ليّكدراو. & ب. ساده. & أ. داريّز داوه. \\
\hline
\end{tabular}

$$
\text { 5. }
$$

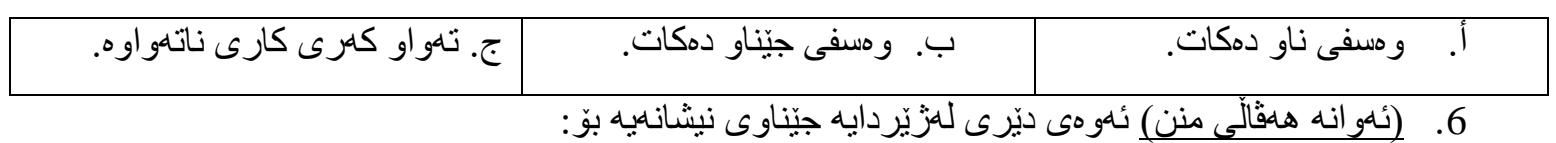

\begin{tabular}{|l|l|l|}
\hline \multicolumn{1}{|c|}{ دوّى دوور. } & دوور ونزيِك. \\
\hline
\end{tabular}

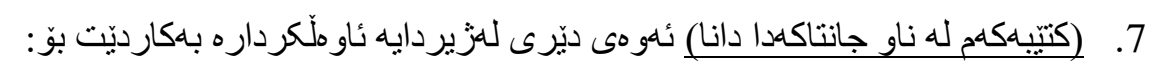

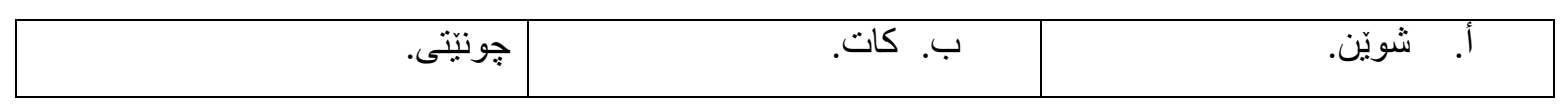

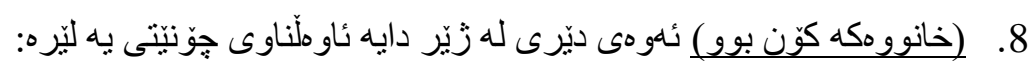

أ.

